\title{
Another look at the comparisons of the health systems expenditure indicators
}

Guillem Lopez-Casasnovas ${ }^{1,2}$, Laia Maynou-Pujoràs ${ }^{3,4,5,6}$, Marc Saez $^{3,4,1}$

${ }^{1}$ Center for Research in Health and Economics (CRES), Universitat Pompeu Fabra, Barcelona.

${ }^{2}$ Department of Economics and Business. Universitat Pompeu Fabra, Spain.

${ }^{3}$ Research Group on Statistics, Econometrics and Health (GRECS), University of Girona, Spain.

${ }^{4}$ CIBER of Epidemiology and Public Health (CIBERESP), Spain.

${ }^{5}$ Universitat Autonoma de Barcelona (UAB), Spain.

${ }^{6}$ London School of Hygiene and Tropical Medicine, UK

Corresponding author:

Prof. Marc Saez, PhD, CStat, CSci

Research Group on Statistics, Econometrics and Health (GRECS)

University of Girona

Campus de Montilivi, 17071 Girona

Tel 34-972-418338, Fax 34-972-418032 http://www.udg.edu/grecs.htm e-mail: marc.saez@udg.edu 
Manuscript (excluding all authors contact details)

Click here to download Manuscript (excluding all authors contact details): Manuscript.doc Click here to view linked References

Another look at the comparisons of the health systems expenditure indicators 


\section{Abstract}

For policy purposes expenditure in health systems of extremely different natures are often compared without having a clear question to be addressed in such a comparison. For instance, comparisons made among OECD countries which have differing levels of development, and/or where the fusion of public and private finance differ; along with their sources of revenue, their finance levels and their degree of taxes and co-payments. Our objective in this paper is to analyze the factors that complicate international comparisons of health care expenditure across countries. We comment on some of these issues and shows how results and the interpretation of the gaps differ according to the refinements we make to the sampling and sub-sampling, as well as the definition of the variables we adopt.

We considered as dependent variables total and health care expenditure per capita and as a percentage of GDP with and without out-of-pocket payments. We analyse the (complete) OECD sample for the period 2000-2010, as well as three sub-samples (European Union, countries with the Bismark model and countries with the Beveridge model).

After calculating the means of the dependent variables, both without weights and weighting by GDP and population, we specified two different panel data models to explain the variation in the dependent variables, including as explanatory variables those that are most likely to affect health expenditure. Although other countries are mentioned in this paper, we take Spain as our example.

We show how the results and the consequent interpretations of the gaps can differ according to the refinements we introduce into the sample and subsamples; akin to the adjustments we are willing to make to the definition of the variables we choose to adopt. We show how Spanish ratios, as example, are generally well above those expected.

In conclusion, there is a need for a better understanding of the settings of any comparison, along with a more appropriate sub sampling of the systems being analyzed in order to align any demand to the financial capabilities of the health care sector.

Key words: health spending, country finance comparisons, OECD data. 


\section{1.- Introduction}

In the literature about health system comparisons, it is a standard practice to take the simple average of representative figures, i.e., health care expenditure (HE hereafter) obtained from international databases (such as the OECD or EUROSTAT), but with no reference to the size of the countries (demographics, GDP, etc.) (Anderson et al., 2000; Anderson et al., 2001 Reinhardt et al., 2002; Peterson et al. 2007; Anderson et al., 2007; Anderson et al., 2008; Hopkins, 2010; OECD, 2010; Keep, 2011; Squires, 2011; Thomson et al., 2011; Squires, 2012). The first consequence of this is attributing equal weights to, for instance, Cyprus and Germany, or assuming that Japan contributes to the average in the same manner as Denmark. As a consequence, neither an adequate representation of the health expenditure of an 'average European citizen' is reached, nor that of a member of the OECD in the developed world. Figures differ from what basically results in adding the expenses of all these countries and dividing the figure by the total population (or national income) of the corresponding area. Certainly it can be argued that any weighting by GDP or population would give too much weight to Japan or the USA in the OECD comparisons, but the remedy is not equal weighting among the countries.

In addition, the samples compared quite often collect together health systems of a very diverse nature (goals and means) such as Mexico and Sweden, or Portugal and Japan. These groupings also differ in their blend of public and private expenditure, their sources of finance and, for similar public expenditure levels, differ in their tax and co-payment configurations. The reason for this confusion frequently relates to an argument for greater or lower expenditure/finance at the convenience of the advocate. Some of these comparisons lead to some confusion. One cannot take the benchmark (e.g. the simple average figure) from health systems which are not (nor do they want to be) a reference for their own health system structures. This invalidates the subsequent claim that the system 'should' be willing to finance more (or less) health expenditure. Efficiency and equity goals differ among systems. Even for well established equity targets, the idea of equal access, equal consumption or equal outcomes, do not come from identical per capita health expenditure targets. In similar terms, efficiency may incorporate not only a cost consideration target, but also some health improvement and specific citizen satisfaction levels. To appraise comparables a crucial exercise in sub-sampling and, above all, being clear about the question to be answered by the comparison needs to be made. For instance, if we compare Spanish HE to the corresponding HE of an average EU citizen, it seems clear we should use figures weighted by population. Whereas, if we compare the average figures of Spain and the UK the relevant comparison would be with a figure from the UK equivalent to a time when its population size or development level was similar to that of Spain today.

Then, if we compare particular disbursements of HE (e.g. salaries) and in general the cost of the inputs, the reference to GDP is justified as salaries constitute some of its components. However, if we take pharmaceutical costs for example, GDP may not be an acceptable ratio as prices, and perhaps even prescription levels do not follow a deflated GDP stance. Instead prices tend to 
be uniform because of reference pricing, and quantities are moved by various types of arbitrages and parallel trade. In this case, per capita spending should be the reference; at least among equally developed and single market areas.

Besides, if we want to capture a more individual based welfare benefiting from $\mathrm{HE}$, then we should consider the way this is financed. Taxes create deadweight losses, whereas prices under willingness to pay (WTP) may reflect that the value is at least the cost it represents to the purchaser. Therefore, comparing net $\mathrm{HE}$ to co-payments and health care service prices may be better units to evaluate. Obviously, the analysis of public $\mathrm{HE}$ and private $\mathrm{HE}$ may follow a different track in the value we award to their income elasticity, with GDP being a proxy for some other variables such as education and housing. For these reasons, we must be careful with how differences in private finance, and out-ofpocket payments (OPPs) in particular are considered, principally for those equity aspects of the comparisons. For example, a country with larger OPPs because of their expenditure on drugs purchased under reference pricing cannot be understood as a conditioner of access to care with effects on health outcomes. If bioequivalence principles are in place, then a brand drug price OPP over the price of a generic drug cannot be seen as a path to health inequality. The opposite would be the case if the extra cost were to be financed from general taxation since the welfare burden of taxes would run against marginal benefits being null. Along similar lines, countries with universal and quite comprehensive coverage do not leave much room for assessing private expenditure on services concurrent to public services as a health care inequality. The share of public over total expenditure may also be a control variable for comparisons. In Less Developed Countries (LDC) this may certainly be the case since complementary coverage becomes a sort of social and almost compulsory payment given the low extent of public coverage. However, this not true for more homogeneously developed countries (DC), for instance the EU, where substitute and supplementary private care are more prevalent purely because of higher income elasticity (conditions for discretionary spending on luxury items). As a consequence, in DC rewards for private insurance of concurrent public services, or for non health related quality aspects of care, should not be accounted for as private expenditure that conditions health outcomes. This perhaps may not be the case for effective, (but not cost effective), services beyond public coverage, but the impact of this is likely to be low. It would actually imply that public services are not well prioritised since, in general, going private by vacating the public waiting list should not generate large impacts on health results.

Finally, comparisons should be adjusted by factors such as premature births, percentage of population overweight, suicide rates, prevalence of smoking and so on. It should be noted that when those variables are accounted for in the estimated comparison for example, we are assuming that they are external variables for which the health systems are not responsible, since these variables are neutralized in the residuals of the estimation. This may be controversial, for instance for smoking or dieting (otherwise components of an individual's welfare), or for low weight premature births (given society's desire to fight for the survival of these babies independent of how likely this survival may be). 
In summary, we postulate that comparisons of HE need to account for all these factors if the estimation's outcomes are to be considered for effective policy making. Our objective in this paper is to analyze the factors that complicate international comparisons of health care expenditure across countries. We seek to reflect the controversial issues surrounding health system comparisons by testing how results differ in keeping with the refinements that the policy analyst is willing to make. We endeavour to do this by (i) sampling and sub-sampling for a more ex ante homogeneous comparison; by (ii) taking weighted averages as the benchmark of some comparisons, either by adopting GPD or population weights as the reference unit of comparison according to the cases being examined; through (iii) a better identification and definition of the variable considered to reflect the analysis we seek to perform; and by (iv) the consideration we are willing to give to the econometric analysis of some of the external factors that affect our comparisons and that may result in the citizen's choice for individual welfares other than health.

In the following sections we take the Spanish case as our reference and we demonstrate how the results and their interpretation change when we apply the features previously described. We plot some of the results and then explain how to interpret them without violating common sense.

\section{2.- Methods}

\section{Data setting}

For the purpose of our analysis, we considered dependent variables as; i) total health expenditure per capita (US\$ PPP) and ii) as a percentage of GDP; iii) as public health expenditure per capita (US\$ PPP,) and iv) as a percentage of GDP. In all cases, we also considered these four variables minus (household) out-of-pocket payments on health that, according to the OECD, 'comprise costsharing, self-medication and other expenditure paid directly by private households, irrespective of whether contact with the health care system was established on referral or on the patient's own initiative' (OECD Health Data, 2001).

We analyse the (complete) OECD sample comprised of Australia, Austria, Belgium, Canada, Chile, Czech Republic, Denmark, Estonia, Finland, France, Germany, Greece, Hungary, Iceland, Ireland, Israel, Italy, Japan, Korea, Luxembourg, Mexico, Netherlands, New Zealand, Norway, Poland, Portugal, the Slovak Republic, Slovenia, Spain, Sweden, Switzerland, Turkey, the United Kingdom, and the United States, for the period 1960-2011 (source: OECD OECD Health Data, 2012; OECD Factbook, 2012- and EUROSTAT EUROSTAT, 2013-); as well as three sub-samples of the following criteria:

1.- Member of the European Union (21 countries)

2.- The Bismarck model (15 countries): Austria, Belgium, Chile, the Czech Republic, Estonia, France, Germany, Hungary, Israel, Japan, Luxembourg, Netherlands, the Slovak Republic, Slovenia, Switzerland 
3.- The Beveridge model (15 countries): Denmark, Finland, Greece, Iceland, Ireland, Italy, Korea, Mexico, New Zealand, Norway, Poland, Portugal, Spain, Sweden, the United Kingdom; or the Douglas model (3 countries): Australia, Canada, Turkey.

The Bismarck model was established at the end of the $19^{\text {th }}$ century by the reactionary German chancellor Otto von Bismarck during German unification. It is characterized by government guaranteeing health benefits through mandatory fees, although patients pay insurance premiums to local/regional sick funds. The Beveridge model, on the other hand, was established in the United Kingdom in 1948 by Lord Beveridge as the National Health Service (NHS). Its central characteristic is public health funding, which comes from the state's general budget, through general taxation. The Douglas model is a combination of the Bismarck and the Beveridge model. While the Douglas model may have private doctors and private hospitals (unlike the Beveridge model), it also has public funding because the insurance premiums are deducted from the payroll (Clairoux, 2012).

The purpose of the sampling was to compare systems that, in principle, share a similar political nature. Here the objective was to take an average value for comparisons that correspond to the nature of the health system we were referring to.

\section{Descriptive analysis}

First, we computed the means of the dependent variables for the period 20002010 for the OECD (complete) sample and the three sub-samples (Tables 1 and 2). The means were initially computed without assigning any weights (the usual practice) and subsequently weighted by GDP and population; depending on the most appropriate denominator of the dependent variable.

Second, we show the values from 2000 to 2010 of the dependent variables and the explanatory variable for Spain and for those countries that, in the year indicated, had a GDP per capita similar to that of Spain. Here we have only considered those countries operating under the Beveridge model as they (for the most part) correspond to the nature of the Spanish NHS.

\section{Econometric model}

Third, in order to explain the variation in the dependent variables we specified two different mixed models (i.e., panel data models), including as explanatory variables those that are most likely to affect $\mathrm{HE}$ and for which there is less controversy about whether they should be taken as given by the health systems or considered as a part of health policy targets any health system should address.

$$
Y_{i t}=x_{i t}^{\prime} \beta+a_{i}+\tau_{t}+u_{i t}
$$

where the subscript $\mathrm{i}$ denoted country; $\mathrm{t}$ time; $\mathrm{Y}$ was the dependent variable; $\mathrm{x}$ denoted a vector of explanatory variables for country $i$ in time $t$ (1960-2011); $\beta$ 
was a vector of unknown coefficients associated with the explanatory variables in vector $x$; $u$ was a vector of zero-mean error terms; $a_{i}$ captured unobserved individual heterogeneity; and $\tau_{\mathrm{t}}$ capture temporal effects.

While the (unobserved) individual heterogeneity captured country-specific time invariant effects not included in $\mathrm{x}$, the temporal effects $\tau_{\mathrm{t}}$ were common to all countries (for simplicity, for now, we have not included specific temporal effects for each country, that is to say, an interaction term).

The specific explanatory variables were:

gdp_pc: $\quad$ GDP per capita US dollars PPPs

pub_exp: Public health expenditure, percentage of total health expenditure

pop: $\quad$ Population

females: Percentage of females

pless15: $\quad$ Percentage of population less than 15 years

pover75: $\quad$ Percentage of population 75 years old or over

tobacco: Tobacco consumption, percentage of population who are daily smokers 15 years and older

alcohol: $\quad$ Alcohol consumption, Litres per capita (age 15+)

obesity: $\quad$ Obesity in population (self-reported), \% of total population

hlthcdasr: Mental and behavioural disorders (ICD10: F00-F99).

unemp: Unemployment

From the review of Gerdtham and Jönsson (2000), on the determinants of health expenditure in OECD countries, there has been very large literature on the determinants of health expenditure. Among them we can cite, for example, Jönsson and Eckerlund (2003); Oliveira \& De la Maisonneuve, 2006, OECD (2006) and, more recently, Baltagi and Moscone (2010). According to the OECD such determinants could be classified into two main factors: nondemographics and demographics (OECD, 2006; Oliveira and De la Maisonneuve, 2006; Mesa, 2011). It has been found that per capita income is the main non-demographic driver of health expenditure (Gerdtham and Jönsson, 2000, Getzen, 2000; Economic Policy Committee and the European Commission, 2006; OECD, 2006). Public health expenditure (as percentage of total health expenditure) captures the effect of the public sector as a driver of total expenditure.

Another major demographic driving force includes aging of the population, population's size (pop, in our case) and age/gender-specific utilization of health care (females in our case) (Gerdtham and Jönsson, 2000; Getzen, 2000). Commonly used age structure indicators are the share of young (for instance under 15 years) and old people (for instance, above 75 year) over total population.

Furthermore, it has been argued that health risks such as tobacco use, excessive alcohol consumption and unhealthy body weight (obesity in our 
case), as they contribute to the development of chronic health problems (see for instance, Sturm et al., 2013) as well as mental illnesses (Bloom et al., 2011), as the leading causes of disability (WHO, 2011), which carry a higher level of health expenditure.

We used the standardised death rate because 'mental and behavioural disorders' was included as a proxy of (standardised death rate) suicides; of which statistics were missing in most of countries for most of the period. In addition, the unemployment rate was also introduced in the models as a proxy of suicides together with (standardised death rate) mental health deaths, because the latter was not available for any of the countries before 1994 and only for some of the countries after that year.

In particular, starting from model (1), we specified model (2a) for total health expenditure and total health expenditure minus out-of-pocket payments, as a percentage of GDP; and for public health expenditure and public health expenditure minus out-of-pockets payments, as a percentage of GDP:

$Y_{i t}=\beta_{0 i t}+\beta_{1 i j} \log \left(g d p_{-} p c\right)+\beta_{2}$ pub_exp $\exp _{i t}+\beta_{3}$ females $_{i t}+\beta_{4}{\text { pless } 15_{i t}+}+$

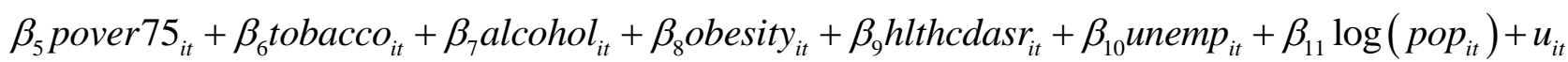

and model (2b) for total health expenditure per capita US\$ PPP and total health expenditure per capita minus out-of-pocket expenditure; public health expenditure per capita US\$ PPP and public health expenditure per capita minus out-of-pocket expenditure:

$$
\begin{aligned}
& \log \left(Y_{i t}\right)=\beta_{0 i t}+\beta_{1 i j} \log \left(\text { gdp } \_ \text {pc }\right)+\beta_{2} \text { pub_exp }_{i t}+\beta_{3} \text { females }_{i t}+\beta_{4}{\text { pless } 15_{i t}+}+ \\
& \beta_{5}{\text { pover } 75_{i t}+\beta_{6} \text { tobacco }_{i t}+\beta_{7} \text { alcohol }_{i t}+\beta_{8} \text { obesity }_{i t}+\beta_{9} \text { hlthcdas }}_{i t}+\beta_{10} \text { unemp }_{i t}+u_{i t}
\end{aligned}
$$

Note that some of the coefficients have subscripts, in particular the coefficient associated with GDP, $\beta_{1}$, In fact, we specify random coefficient panel data models (Hsiao and Pesaran, 2008) or, in mixed model terminology, we allow (some of the) coefficients to be random effects (Pinheiro and Bates, 2000). In other words, we have allowed them to be different for the various levels we have considered. In both cases, we have considered three levels: country (denoted by i); model (Bismarck, Beveridge-Douglas, other - i.e., out-of-pocket and denoted by j) and time t.

In particular, we have allowed random effects for the intercept (which varied per country and time) and for the coefficient of interest, i.e., that associated with GDP (which varied per country and model). Allowing the intercept was different for each country, we assumed that there were factors other than explanatory variables specific to each country that could explain the variation in health expenditure. Note that here we allowed the interaction, that is to say the existence of the country specific effects which varied over time. Furthermore, we assumed that the effect of GDP per capita on health expenditure could we be different in each of the models of health management (Bismarck, Beveridge- 
Douglas, out-of-pocket) and, therefore, we allowed the coefficient of interest (that associated with GDP) varied accordingly (i.e. by model). Moreover, by allowing this coefficient be different for each country we allowed that relationship between healthcare expenditure and income not to be lineal.

Also, we controlled for the time dependency (through the variation of the independent term in time) and the heteroskedasticity (weighting for the population of each country throughout the period analysed).

In this paper we are interested in the residuals of the models (2a) and (2b) for the eight dependent variables (i.e., the differences between the observed and the expected value of the dependent variables) which were adjusted for all explanatory factors, for time dependency and for non-constant variance. In other words, we do not care so much about the variation of health expenditure but whether the observed health expenditure corresponded to the expected, again controlling for explanatory variables, time dependency and non-constant variance. Only by controlling these factors, we will be able to undertake international comparisons of health care expenditure across countries.

To estimate the models we have chosen to use a conditional approach and not a marginal approach, for example, the within estimators (also 'fixed effects model'). Three were the reasons that made us doing so. First, the fixed effects estimators eliminate unobserved individual heterogeneity. In our case, we explicitly assumed that there were country-specific factors explanatory of the variation in dependent variables. Secondly, the fixed effects estimators do not allow, as we do, interaction, i.e. the existence of the country specific effects which varied over time. Third, and most important, in mixed models, such as those we have used, unless the assumption of independence between the regressors and the random effects is fulfilled, the estimates of the coefficients will be inconsistent (Hsiao and Pesaran, 2008).

However, Hsiao et al. (1999) show that, even in this case, the use of a Bayesian approach performed fairly well. In fact, this is due to the greater flexibility of the Bayesian estimation, a consequence of its hierarchical strategy. Within the (pure) Bayesian framework, we followed the Integrated Nested Laplace Approximation (INLA) approach (Rue et al., 2009; Schrödle and Held, 2011).

All analyses were performed with the free software $R$ (version 3.0.1) (R Development Core Team, 2013), made available through the INLA library (Rue et al., 2009; The R-INLA project, 2013).

\section{3.- Results}

\section{Descriptive}

Table 1a depicts the total Spanish HE as a percentage of GDP. Note that, without any adjustment, it has almost caught up with the unweighted OECD average. This was the case particularly after the start of the crisis (2008), and likely due to the denominator effect; that is, GDP dropped more than the numerator (HE). However, the weighted average (weighted by GDP) reopened 
the gap, as a result of the up-bias caused by the data from the USA and Japan, more than fully offsetting Mexico and other LDCs figures in the OECD sample. A very similar behaviour is observed when we consider HE minus out-of-pocket payments (Table 1b).

However, the difference is clearly reduced if we only take Public HE (Tables 2a and $2 \mathrm{~b}$ ), and it is even lower if public figures are taken net without out-of-pocket payments (Table $2 \mathrm{~b}$ ). This probably has to do with the magnitude of the USA figures in the OECD sample, and in particular with the larger share of its private expenditure on health care affecting the total HE ratios. To the contrary, the effect disappears when we compare average and individual data of health systems in a rather more homogeneous arena: either that of the European Union (EU) or, for an even more parallel group, developed EU countries with similar systems. In Spain's case if we take the sample of Beveridge type models as the reference for the comparisons and once we have adjusted for GDP differences, then Spain is (despite having a lower GDP) above and not below the average, even for the weighted averages, GDP or population, respectively.

By starting the analysis with the OECD sample we can observe that if we weight the average value of the sample by population (searching for a sort of 'representative' citizen of the area), the Spanish total per capita HE remained far from the OECD reference value. If we adopt Public HE instead of Total HE, the Spanish figure came closer to that of the OECD and was always above the Beveridge standard but clearly below the Bismarck sub-sample average. This was particularly the case if we subtract the Public HE variable from the amount of finance raised from sources other than taxes. The French and German population data were crucial in increasing the distance to the benchmark. However, in all the cases the Spanish value was either at or above the level of the 'last resort' Beveridge reference for any of the alternative weighting factors. If population and not GDP is the weight adopted (see Tables 1c and 1d), the gap between Spain and the Bismarck model countries was not so large, likely due to the influencing factor of a highly populated and relatively wealthy Germany. However, in comparison to the Beveridge type of models, the difference with regard to the GDP weight is even larger, and is due to the relatively high population of the UK compared to that of Spain (rather than different per capita incomes) (Tables 2a and 2c)

In fact, if the variable we compare is Public HE, defined as a percentage of GDP (Table 2a), while Spain may have surpassed the unweighted OECD average, it did not outperform the weighted average nor the EU Public HE average. The Bismarck models lead this average: indeed the figure is quite similar for the weighted average of GDP for the Beveridge type of models despite the fact that the denominator in those models tends to be greater than that of the Spanish GDP (and hence having a lower ratio). Similar results are shown in Tables $2 \mathrm{c}$ and $2 \mathrm{~d}$.

In addition to the cases already mentioned, we can compare the expenditure figures for Spain (with regards to the GDP figures) for the stratifications that correspond to the time those OECD countries had the GDP per capita for each of the years in the Spanish case (Table 3). In Table 3 the reader can verify the 
value of those variables and the year and the specific country of comparison with regards to per capita GDP.

\section{Results of the estimation of the models}

Finally, the regression estimation allows for those 'legitimate' exogenous factors that affect the residuals to be adjusted. Indeed, the actual values compared to those predicted evolved from refining the comparison of the health systems along the lines of the reasoning in this paper. In other words, by extending the analysis to those countries with greater similarities, and/or adjusting for the factors indicated above. As can be seen in Figures 1 to 4, the Spanish ratios were generally well above the expected ratios from 2007 and below the expected until 2004.

Figures 1 to 4 show the estimation results from equations (1) and (2) according to the regressors that were finally considered. For all of the OECD health systems being compared, and in particular for the total HE indicator (GDP adjusted and sub-sampled for Beveridge type of models (Figure 1b)), we observe how Portugal was clearly losing ground against the standard as a result of the crisis. However, this did not seem to be the case for Spain. Sweden was on the predicted line and Iceland was the clear outlier of the convergence process with decreasing values and with an increasing gap with regard to the benchmark. Finally, note that with the crisis the UK expenditure ratio changed by moving from below the standard to above it. This is most likely by virtue of the higher resilience of HE being well above its GDP fluctuation.

Figure $2 \mathrm{~b}$ offers the analysis in terms of total $\mathrm{HE}$ in relative per capita terms and with regard to the Beveridge subsample. We see that the differences under this approach are narrow. Iceland's population (rather than Ireland's) was clearly suffering most because of the economic crisis, as did Sweden's in per capita terms, although to at a lesser extent.

Figure $3 \mathrm{~b}$ focuses on Public HE as a percentage of GDP. The UK and Ireland proved a dominant force by being well about the benchmark in the Public HE over total HE data. Moreover, the positive gap increased with the economic recession due to a lowering GDP. In per capita terms (Figure 4b), Iceland and Italy (but not Spain) were the countries most seriously affected by the crisis. Not surprisingly, Spain exhibited, even in 2010, a very low share of public expenditure not financed by taxes. Only for the residuals in Figure 4c of Public $\mathrm{HE}$ in per capita terms and for a standard weighted by demographics do we see a reverse of that result due to the crisis.

\section{4.- Discussion}

In general, as a result of the estimation of the equations (1) and (2), the Spanish indicators reflecting the difference between the actual and the predicted values from the estimation equation from the appropriate samples (Figures 1a, 1c; 2a, 2c; $3 a$ and 3c) show positive residuals (from 2007). This goes against the common claim that Spanish levels of expenditure and finance are well below most of the conventional standards. It is particularly so when we subtract the 
portion that is financed out-of-pocket from HE. We believe that this finance component offers a different rationale to that derived from general taxation. Moreover, that result is enhanced when the benchmark for the comparison is a population weighted mean (when searching for a type of 'representative' citizen of our sample being considered). If GDP is the weight results are rather similar (in identifying a sort of median income citizen) albeit with a distinct contrast in the years of the crisis (Figure 4a). Both measures may be disputed but we think that they are more adequate than the simple 'average income'. Finally, we subsample the estimations according to the political nature of the health systems as we believe that it does not make sense to derive benchmarks from health systems' expenditure that society is not willing to emulate.

We chose to leave the controversial arena of just what adjustment factors should join the estimated equations open. This is because society's views on what a health system should cover or whatever is endogenous to health policies and to community changes surpass the purpose of this paper.

As can be seen, the policy making consequences of the analysis differ dramatically in terms of these first arguments for health system comparisons.

\section{5.- Concluding remarks}

In this paper we have seen some of the issues that complicate the comparison of health system indicators. We have shown how the results and the consequent interpretations of the gaps can differ according to the refinements we introduce into the sample and sub-samples; akin to the adjustments we are willing to make to the definition of the variables we choose to adopt. The example we use, although some other countries are also mentioned, is the Spanish case and the oft heard claim that comparative standards justify increased public health care spending. The prognosis of the analysis contradicts the former assessment because the Spanish figures are generally well above those anticipated; particularly when the terms of reference are from countries with similar Beveridge models and accounting for the GDP that Spain had in each particular year. We end by showing additional analysis coming from a more sophisticated econometric estimation. We also leave open for discussion just which particular variables should be taken as regressors. These variables should be considered in light of the questions we want to answer with the estimation and should depend on the control variables we want to neutralise in the health systems when we correlate the results.

As has been seen, the Spanish ratios are generally well above those expected (from 2007). This weakens, at least from this perspective, the general claim for increasing expenditure in health care in Spain and contradicts the conventional argument for greater (rather than better) health expenditure. As we have expressed in this paper, there is indeed a need for a better understanding of the settings of any comparison, along with a more appropriate sub sampling, according to the 'political' nature of the health systems, of the systems being analyzed in order to align any demand to the financial capabilities of the health care sector,. 
Acknowledgements

We appreciate the comments of two anonymous reviewers that, without doubt, help us improve our work. 


\section{References}

Anderson, G.F., Hurst, J., Hussey, P.S. and Jee-Hughes, M. (2000) Health spending and outcomes: Trends in OECD countries, 1960-1998. Health Affairs, 19(3), 150-157.

Anderson, G.F. and Hussey, P.S. (2001) Comparing health system performance in OECD countries. Health Affairs, 20(3), 219-232.

Anderson, G.F., Frogner, B.K. and Reinhardt, U.E. (2007) Health spending in OECD countries in 2004: An update. Health Affairs, 26(5), 1481-89

Anderson, G.F. and Frogner, B.K. (2008) Health spending in OECD countries: Obtaining value per dollar. Health Affairs, 27(6), 1718-1727.

Baltagi, B.H. and Moscone, F (2010). Health care expenditure and income in the OECD reconsidered: Evidence from panel data. Economic Modelling, 27(4), 804-811.

Bloom, D.E., Cafiero, E.T., Jané-Llopis, E., Abrahams-Gessel, S., Bloom, L.R., Fathima, S., Feigl, A.B., Gaziano, T., Mowafi, M., Pandya, A., Prettner, K., Rosenberg, L., Seligman, B., Stein, A. and Weinstein, C. (2011). The Global Economic Burden of Non-communicable Diseases. Geneva: World Economic Forum.

Clairoux, N. (2012) Where is the best health care system in the world?.Medical Library Association (MLA) Annual Blog [Available at: http://npc.mlanet.org/mla12/?p=1322, last accessed on August 3, 2013].

Economic Policy Committee and the European Commission (2006). The impact of ageing on public expenditure: projections for the EU25 Member States on pensions, health care, long-term care, education and unemployment transfers (2004-2050). European Economy. Special Report no 1/2006.

EUROSTAT

[Available

at: http://epp.eurostat.ec.europa.eu/portal/page/portal/statistics/search database, last accessed on August 3, 2013].

Gerdtham,U.G, and Jönsson, B. (2000). International comparisons of health expenditure: theory, data and econometric analysis. In Culyer, A.J. and Newhouse, J.P. (eds). Handbook of Health Economics, Vol. 1. Amsterdam, Elsevier, pp.11-53.

Getzen, T.E. (2000). Health care is an individual necessity and a national luxury: applying multilevel decision models to the analysis of health care. Journal of Health Economics, 19, 259-270. 
Jönsson, B. and Eckerlund, I. (2003). Why do different countries spend different amounts on health care? In A Disease-based Comparison of Health Systems. What is Best and What Cost?, OECD, Paris, pp. 107-120 [Available at: http://browse.oecdbookshop.org/oecd/pdfs/product/8103031e.pdf, st accessed on January 16, 2014].

Hopkins, S. (2010) Health expenditure comparisons: Low, middle and high income countries. The Open Health Services and Policy Journal, 3, 111-117 [Available http://www.benthamscience.com/open/tohspj/articles/V003/111TOHSPJ.pdf, last accessed on September 14, 2013].

Hsiao, C., Pesaran, M.H. and Tahmiscioglu, A.K (1999). Bayes estimation of short-run coefficients in dynamic panel data models. In Hsiao, C., Lee, L.F., Lahiri, K. And Pesaran, M.H. (eds). Analysis of Panels and Limited Dependent Variables Models. pp. 268-206. Cambridge University Press: Cambridge.

Hsiao,C.and Pesaran, M.H. (2008) Random coefficient panel data models. In Mátyás, L. and Sevestre, P. (eds). The Econometrics of Panel Data. Advances Studies in Theoretical and Applied Econometrics Vol. 46. Berlin, Heidelberg: Springer, pp. 185-213.

Keep, M. (2011) Health Expenditure: International Comparisons. London: House of Commons Library, Standard Notes SN/SG/2584 [Available at: http://www.parliament.uk/Templates/BriefingPapers/Pages/BPPdfDownload.asp $\underline{x}$ ?bp-id=SN02584 last accessed on September 14, 2013].

Mesa $L$ (2011). Determinants of health care expenditure: the Colombian case. Apuntes del CENES, 30(52), 87-102.

OECD. (2006). Projecting OECD health and long-term care expenditures: what are the main drivers? Economics department Working papers 477 [Available at: http://www.oecd.org/eco/public-finance/36085940.pdf last accessed on January $16,2014]$.

OECD (2010). Health care systems: Getting more value for money. OECD Economics Department Policy Notes No.2 [Available at: http://www.apha.org/NR/rdonlyres/7EE65F33-9F4E-4EBF-8554-

DE29461A11F8/0/OECDhealthsystemscompare.pdf last accessed on September 14, 2013].

OECD Health Data 2001: A Comparative Analysis of 30 Countries, OECD, Paris, 2001, data sources, definitions and methods. [Available at: http://stats.oecd.org/glossary/detail.asp?ID=1967, last accessed on September 14, 2013].

OECD Health Data 2012 [Available at: http://stats.oecd.org/Index.aspx?DataSetCode=SHA, last accessed on August 3, 2013]. 
OECD Factbook 2012 [Available at: http://www.oecdilibrary.org/economics/oecd-factbook-2011-2012 factbook-2011-en; last accessed on August 3, 2013].

Oliveira, J. and De la Maisonneuve, C.(2006). The drivers of public expenditure on health and long-termcare: an integrated approach. OECD Economic Studies 43.

Peterson, C.L. and Burton, R. (2007) U.S. Health Care Spending: Comparison with other OECD Countries. Washington DC: Congressional Research Service [Available at: digitalcommons.ilr.cornell.edu/key_workplace/311/, last accessed on September 14, 2013].

Pinheiro, J.C. and Bates, D. (2000) Mixed-effects Models in S and S-PLUS New York: Springer-Verlag.

R Development Core Team (2013). R: A language and environment for statistical computing. Vienna, Austria: R Foundation for Statistical Computing, ISBN 3,900051,07,0 [Available at: http://www.r-project.org/ last accessed on August 3, 2013].

The R-INLA project [Available at: http://www.r-inla.org/, last accessed on August 3, 2013].

Reinhardt, U.E., Hussey, P.S. and Anderson, G.F. (2002) Cross-national comparisons of health systems using OECD data, 1999. Health Affairs, 21(3), 169-181.

Rue, H., Martino, S. and Chopin, N. (2009) Approximate Bayesian inference for latent Gaussian models by using integrated nested Laplace approximations (with discussion). Journal of the Royal Statistical Society, Series B, 71, 319392. [Available at http://www.r-inla.org/papers, last accessed on August 3, 2013]

Schrödle, B. and Held, L. (2011). A premier on disease mapping and ecological regression using INLA. Computational Statistics 26(2):241-258.

Squires, D.A. (2011) The U.S. health system in perspective: A comparison of twelve industrialized nations. The Commonwealth Fund, July 2011, New York.

Squires, D.A. (2012) Explaining high health care spending in the United States: An international comparison of supply, utilization, prices, and quality. The Commonwealth Fund Publication, 1595(10), May 2012, New York [Available at: http://www.commonwealthfund.org/ /media/Files/Publications/lssue\%20Brief/20 12/May/1595 Squires explaining high hlt care spending intl brief.pdf, last accessed on September 14, 2013].

Sturm, R., An, R., Maroba, J. and Patel, D. (2013). The effects of obesity, smoking, and excessive alcohol intake on healthcare expenditure in a comprehensive medical scheme. South African Medical Journal, 103(11), 840844. 
Thomson, S., Osborn, R., Squires, D.A. and Reed, S.J. (2011) International profiles of health care systems 2011. The Commonwealth Fund, Nov. 2011, New York.

World Health Organization (2011). Global status report on non-communicable diseases 2010. Geneva: WHO. 
TABLE 1a.- Total health care expenditure means, as a percentage of GDP, for the complete OECD sample and three sub-samples.

Spain

\section{Expenditure ${ }^{1}$}

$\begin{array}{ll}2000 & 7.20 \\ 2001 & 7.20 \\ 2002 & 7.30 \\ 2003 & 8.20 \\ 2004 & 8.20 \\ 2005 & 8.30 \\ 2006 & 8.40 \\ 2007 & 8.50 \\ 2008 & 8.90 \\ 2009 & 9.60\end{array}$

$$
\text { OECD sample }
$$

\section{GDP $^{2}$}

Expenditure

$\begin{array}{ll}21314.433 & 7.77 \\ 22577.936 & 8.02 \\ 24068.216 & 8.30 \\ 24754.840 & 8.57 \\ 25956.475 & 8.61 \\ 27392.007 & 8.66 \\ 30405.925 & 8.60 \\ 32233.471 & 8.62 \\ 33129.605 & 8.89 \\ 32149.771 & 9.75 \\ 31903.798 & 9.72\end{array}$

EU countries sub-sample

Expenditure $^{1}$ Weighted $^{3}$

$\begin{array}{ll}8.20 & 7.71 \\ 8.45 & 7.92 \\ 8.77 & 8.18 \\ 9.01 & 8.49 \\ 9.04 & 8.59 \\ 9.05 & 8.69 \\ 8.95 & 8.62 \\ 8.93 & 8.61 \\ 9.16 & 8.90 \\ 10.03 & 9.72 \\ 10.15 & 9.57\end{array}$

7.93
8.14
8.44
8.68
8.79
8.84
8.74
8.68
8.94
9.81
9.83

Bismarck model countries

Expenditure ${ }^{1}$ Weighted $^{3}$

7.91

8.04

8.26

8.63

8.69

8.66

8.51

8.51

8.73

9.54

9.64

8.29
8.42
8.71
8.96
9.04
8.97
8.78
8.71
8.86
9.73
10.16

10.16
Beveridge - Douglas model countries Expenditu Weighted
$\mathrm{re}^{1}$

$\begin{array}{ll}7.33 & 7.65 \\ 7.66 & 7.98 \\ 7.96 & 8.30 \\ 8.12 & 8.48 \\ 8.16 & 8.49 \\ 8.26 & 8.54 \\ 8.28 & 8.54 \\ 8.29 & 8.54 \\ 8.60 & 8.84 \\ 9.47 & 9.68 \\ 9.29 & 9.49\end{array}$

TABLE 1b.- Means of total health care expenditure minus out-of-pocket payments, as a percentage of GDP, for the complete OECD sample and three sub-samples.

Spain

Expenditure $^{1}$

$\begin{array}{ll}2000 & 5.50 \\ 2001 & 5.48 \\ 2002 & 5.57 \\ 2003 & 6.32 \\ 2004 & 6.34 \\ 2005 & 6.47 \\ 2006 & 6.63 \\ 2007 & 6.77 \\ 2008 & 7.10 \\ 2009 & 7.77 \\ 2010 & 7.71\end{array}$

GDP $^{2} \quad$ Exp $21314.433 \quad 6.15$ $22577.936 \quad 6.39$ $\begin{array}{ll}24068.216 & 6.67\end{array}$ $24754.840 \quad 7.00$ $25956.475 \quad 7.07$ $27392.007 \quad 7.09$

$30405.925 \quad 6.96$ $32233.471 \quad 6.98$

$33129.605 \quad 7.28$

$\begin{array}{ll}32149.771 & 7.96 \\ 31903.798 & 7.22\end{array}$
OECD sample

Weighted
6.65
6.87
7.20
7.46
7.52
7.51
7.39
7.37
7.62
8.33
8.51

\section{Expenditure $^{1}$}

6.46

6.34

6.60

7.03

7.19

7.23

7.15

7.13

7.33

8.06

7.89

Weighte
6.46
6.64
6.95
7.27
7.45
7.46
7.36
7.29
7.47
8.24
8.20

EU countries sub-sample

Expenditure $^{1}$ Weighted $^{3}$

6.40

6.46

6.71

6.99

7.12

7.09

6.94

6.92

7.16

7.87

7.96
6.78

6.84

7.17

7.36

7.52

7.47

7.29

7.21

8.17
Bismarck model countries

Expenditure $^{1}$ Weighted $^{3}$

$5.65 \quad 6.08$

$6.00 \quad 6.41$

$6.28 \quad 6.71$

$\begin{array}{ll}6.58 & 6.97\end{array}$

$\begin{array}{ll}6.62 & 6.97\end{array}$

$\begin{array}{ll}6.68 & 6.99\end{array}$

$6.57 \quad 6.93$

$6.60 \quad 6.96$

$\begin{array}{ll}6.95 & 7.23\end{array}$

$\begin{array}{ll}7.56 & 7.86\end{array}$

$7.67 \quad 7.82$ 
TABLE 1c.- Means of total health care expenditure, per capita, for the complete OECD sample and three sub-samples.

Spain

\section{Expenditure ${ }^{1}$}

$2000 \quad 1537.80$

$2001 \quad 1635.00$

$2002 \quad 1745.00$

$2003 \quad 2025.60$

$2004 \quad 2135.10$

$2005 \quad 2274.10$

$2006 \quad 2552.50$

$2007 \quad 2738.60$

$2008 \quad 2965.50$

20093096.70

$2010 \quad 3055.70$

(x)

EU countries sub-sample Bismarck model countries

OECD sample

$\begin{array}{cll}\text { GDP }^{2} & \text { Expenditure }^{1} & \text { Weighted }^{3} \\ 21314.433 & 1887.56 & 2436.818 \\ 22577.936 & 2016.31 & 2611.321 \\ 24068.216 & 2178.61 & 2799.579 \\ 24754.840 & 2294.33 & 2982.301 \\ 25956.475 & 2440.89 & 3158.387 \\ 27392.007 & 2564.25 & 3352.979 \\ 30405.925 & 2749.81 & 3575.855 \\ 32233.471 & 2910.95 & 3799.707 \\ 33129.605 & 3103.08 & 3983.382 \\ 32149.771 & 3322.79 & 4349.243 \\ 31903.798 & 3328.52 & 4637.152\end{array}$

\section{Expenditure ${ }^{1}$}

1805.82

1930.70

2099.70

2225.63

2376.58

2500.45

2700.20

2856.64

3057.53

3220.38

3135.37

Weighted $^{3}$
1967.855
2108.038
2247.732
2375.435
2497.218
2646.263
2847.404
2997.065
3184.312
3351.918
3376.740

Expenditure ${ }^{1}$

1864.41

1960.15

2116.50

2232.71

2372.16

2468.37

2630.39

2791.87

2978.04

3141.27

3125.48
Weighted $^{3}$ 2224.326 2349.871

2483.167

2611.620

2723.099

2878.852

3039.393

3217.163

3389.378

3578.895

3967.663
Beveridge - Douglas

model countries

Expenditure $^{1}$ Weighted $^{3}$

$\begin{array}{ll}1745.57 & 1273.417\end{array}$

$1889.48 \quad 1378.778$

$2041.63 \quad 1462.312$

$2140.20 \quad 1546.297$

$2280.73 \quad 1657.272$

$2412.84 \quad 1773.899$

$2607.25 \quad 1943.657$

$2756.21 \quad 2066.719$

$2948.53 \quad 2200.413$

$3208.42 \quad 2526.689$

$3174.27 \quad 2497.159$

TABLE 1d.- Total health care expenditure means minus out-of-pocket payments, per capita, for the complete OECD sample and three sub-samples.

Spain

$\begin{array}{ll} & \text { Expenditure } \\ 2000 & 1175.2 \\ 2001 & 1243.7 \\ 2002 & 1331.2 \\ 2003 & 1562.3 \\ 2004 & 1650.3 \\ 2005 & 1772.1 \\ 2006 & 2015.0 \\ 2007 & 2179.8 \\ 2008 & 2367.4 \\ 2009 & 2506.5 \\ 2010 & 2454.6\end{array}$

OECD sample

GDP $^{2}$ 21314.433

22577.936

1940.00

$25956.475 \quad 2076.72$

$27392.007 \quad 2177.48$

$30405.925 \quad 2277.50$

$32233.471 \quad 2413.58$

$33129.605 \quad 2560.47$

$32149.771 \quad 2703.27$

$31903.798 \quad 2690.73$
EU countries sub-sample

Weighted $^{3}$
2047.56
2206.33
2371.59
2674.67
2829.49
3008.33
3043.69
3239.48
3556.29
3721.38
3983.26

\section{Expenditure ${ }^{1}$}

1412.29

1540.53

1685.89

1852.12

2024.08

2121.56

2284.88

2414.81

2550.16

270240

2612.78

Weighted $^{3}$
1648.69
1775.82
1892.94
2032.67
2146.38
2276.82
2449.88
2576.85
2722.03
2880.97
2900.85

Bismarck model countries

Expenditure $^{1}$

1518.91

1590.28

1732.42

1797.06

1970.01

2051.17

2180.39

2307.57

2482.08

2632.75

2615.88

Weighted $^{3}$
1921.28
2029.67
2135.32
2253.98
2352.24
2495.66
2618.18
2777.20
2933.20
3102.79
3485.63

\section{Beveridge - Douglas}

model countries

Expenditure $^{1}$ Weighted $^{3}$

$1384.67 \quad 956.16$

$1533.39 \quad 1063.36$

$1662.98 \quad 1130.18$

$1857.60 \quad 1329.65$

$1962.48 \quad 1428.79$

$2067.18 \quad 1528.76$

$2132.68 \quad 1520.70$

$2265.02 \quad 1620.30$

2369.36 $\quad 1864.84$

$2498.95 \quad 1987.92$

$2445.77 \quad 1954.95$

1 Total health expenditure - Out-of-pocket payments (households) per capita US\$ PPP, US\$ PPP 2 Weighted by GDP per capita US dollars, PPPs, 3 Weighted by population 
TABLE 2a.- Public health care expenditure means, as a percentage of GDP, for the complete OECD sample and three sub-samples.

\begin{tabular}{|c|c|c|c|c|c|c|c|c|c|c|}
\hline & \multicolumn{2}{|c|}{ Spain } & \multicolumn{2}{|c|}{ OECD sample } & \multicolumn{2}{|c|}{ EU countries sub-sample } & \multicolumn{2}{|c|}{ Bismarck model countries } & \multicolumn{2}{|c|}{$\begin{array}{l}\text { Beveridge - Douglas } \\
\text { model countries }\end{array}$} \\
\hline & Expenditure $^{1}$ & GDP $^{2}$ & Expenditure $^{1}$ & Weighted $^{3}$ & Expenditure $^{1}$ & Weighted $^{3}$ & Expenditure $^{1}$ & Weighted $^{3}$ & Expenditure $^{1}$ & Weighted $^{3}$ \\
\hline 2000 & 5.16 & 21314.433 & 5.54 & 5.89 & 5.85 & 6.07 & 5.83 & 6.14 & 5.28 & 5.67 \\
\hline 2001 & 5.13 & 22577.936 & 5.73 & 6.07 & 6.00 & 6.21 & 5.91 & 6.23 & 5.54 & 5.92 \\
\hline 2002 & 5.20 & 24068.216 & 5.94 & 6.33 & 6.20 & 6.45 & 6.10 & 6.48 & 5.77 & 6.18 \\
\hline 2003 & 5.77 & 24754.840 & 6.09 & 6.47 & 6.42 & 6.62 & 6.25 & 6.60 & 5.91 & 6.32 \\
\hline 2004 & 5.79 & 25956.475 & 6.10 & 6.49 & 6.45 & 6.69 & 6.24 & 6.63 & 5.94 & 6.34 \\
\hline 2005 & 5.89 & 27392.007 & 6.13 & 6.50 & 6.53 & 6.73 & 6.23 & 6.60 & 6.00 & 6.37 \\
\hline 2006 & 6.02 & 30405.925 & 6.13 & 6.48 & 6.51 & 6.72 & 6.17 & 6.55 & 6.03 & 6.37 \\
\hline 2007 & 6.11 & 32233.471 & 6.14 & 6.46 & 6.49 & 6.66 & 6.16 & 6.48 & 6.05 & 6.38 \\
\hline 2008 & 6.51 & 33129.605 & 6.39 & 6.70 & 6.74 & 6.87 & 6.38 & 6.66 & 6.33 & 6.65 \\
\hline 2009 & 7.17 & 32149.771 & 7.06 & 7.37 & 7.38 & 7.56 & 7.00 & 7.34 & 7.02 & 7.32 \\
\hline 2010 & 7.12 & 31903.798 & 6.99 & 7.38 & 7.20 & 7.48 & 7.03 & 7.53 & 6.87 & 7.18 \\
\hline
\end{tabular}

1 Public health expenditure as a \% GDP; 2 GDP per capita US dollars, PPPs; 3 Weighted by GDP

TABLE 2b.- Public health care expenditure means minus out-of-pocket payments, as a percentage of GDP, for the complete OECD sample and three sub-samples.

\section{Spain}

Expenditure ${ }^{1}$

$\begin{array}{ll}2000 & 3.46 \\ 2001 & 3.41 \\ 2002 & 3.47 \\ 2003 & 3.89 \\ 2004 & 3.93 \\ 2005 & 4.06 \\ 2006 & 4.25 \\ 2007 & 4.38 \\ 2008 & 4.71 \\ 2009 & 5.34 \\ 2010 & 5.23\end{array}$

OECD sample

GDP $^{2} \quad$ Expenditure $^{1}$ Weighted $21314.433 \quad 3.97$ $22577.936 \quad 4.18$ $24068.216 \quad 4.42$ $24754.840 \quad 4.51$ $25956.475 \quad 4.56$ $27392.007 \quad 4.58$ $30405.925 \quad 4.52$ $32233.471 \quad 4.54$ $33129.605 \quad 4.72$ $32149.771 \quad 5.22$ $31903.798 \quad 5.33$

4.33
4.55
4.83
4.92
4.99
4.99
4.96
4.95
5.08
5.62
5.66

EU countries sub-sample
Expenditure $^{1}$ Weighted $^{3}$

4.46
4.64

4.64

4.87

5.08
5.12

5.15

5.12

5.09

5.17

5.72

5.52
4.78

4.94

5.22

5.32

5.41

5.42

5.41

5.34

5.40

6.00
Bismarck model countries

Expenditure $^{1}$ Weighted $^{3}$

4.54

4.56

4.79

4.62
4.67

4.66

4.60

4.57

4.81

5.34
4.77

4.80

5.12

5.02

5.11

5.10

5.06

4.98

5.20

5.78

5.86

1 Public health expenditure- Out-of-pocket payments (households), \% GDP, 2 GDP per capita US dollars, PPPs 3 Weighted by GDP

\begin{tabular}{ll}
\multicolumn{2}{c}{$\begin{array}{c}\text { Beveridge - Douglas } \\
\text { model countries }\end{array}$} \\
Expenditure & Weighted \\
Exp & Weigh \\
3.62 & 4.09 \\
3.95 & 4.42 \\
4.20 & 4.67 \\
4.38 & 4.85 \\
4.45 & 4.89 \\
4.49 & 4.90 \\
4.41 & 4.85 \\
4.46 & 4.89 \\
4.58 & 4.93 \\
5.05 & 5.40 \\
5.24 & 5.42
\end{tabular}


TABLE 2c.- Public health care expenditure means, per capita, for the complete OECD sample and three sub-samples.

Spain

OECD sample

EU countries sub-sample

Bismarck model countries

Expenditure ${ }^{1}$

GDP $^{2}$

$21314.433 \quad 1350.48$ $22577.936 \quad 1443.79$

$24068.216 \quad 1565.13$

$24754.840 \quad 1639.49$

$25956.475 \quad 1743.01$

$27392.007 \quad 1832.16$

$30405.925 \quad 1979.11$

$32233.471 \quad 2094.97$

$33129.605 \quad 2254.84$

$32149.771 \quad 2428.18$

$31903.798 \quad 2411.88$

2314.10

2266.80
Expenditure $^{1}$ Weighted $^{3}$

1372.63

1440.17

1561.89

1626.65

1719.95

1795.38

$1972.188-1859.35$

$2121.424 \quad 2058.61$

$2255.462 \quad 2171.69$

2331.97

2464.45

2370.05

1891.079

2007.750

2177.656

2289.911

2444.681

1937.05

2050.08

2210.64

2341.83

2605.636

2296.71

1739.061

1939.730

2022.116

2093.561

2223.254

2346.008

2491.502

2627.811

2781.289

3027.111
Beveridge - Douglas

model countries

Expenditure ${ }^{1}$ Weighted $^{3}$

1292.58

1401.31

1518.77

1595.56

1703.43

1799.33

1946.36

2060.92

2218.74

2424.85

2401.09
884.1347

967.2231

1024.757

1082.595

1168.076

1249.629

1373.489

1459.550

1580.099

1834.994

1813.005

TABLE 2d.- Public health care expenditure means minus out-of-pocket payments, per capita, for the complete OECD sample and three subsamples.

Spain Expenditure ${ }^{1}$

$2000 \quad 738.80$

$2001 \quad 772.80$

$2002 \quad 830.30$

$2003 \quad 962.40$

$2004 \quad 1021.90$

$2005 \quad 1111.90$

$2006 \quad 1291.10$

$2007 \quad 1410.10$

$2008 \quad 1571.30$

$2009 \quad 1723.90$

20101665.70
EU countries sub-sample

Expenditure ${ }^{1}$

1039.97

1142.20

1261.35

1341.96

1456.31

1526.83

1660.75

1749.59

1824.60

1946.48

1847.47
Weighted $^{3}$

1205.47

1309.79

1398.74

1472.55

1546.48

1645.83

1788.17

1879.03

1982.40

2122.32

2129.74
Bismarck model countries

Expenditure ${ }^{1}$

1062.51

1109.17

1227.24

1206.49

1317.81

1378.18

1487.05

1565.77

1714.68

1833.30

1787.11
Weighted $^{3}$

1463.88

1550.21

1629.20

1670.14

1722.70

1840.06

1924.80

2051.54

2171.63

2305.18

2545.08
Beveridge - Douglas

model countries

Expenditure $^{1}$ Weighted $^{3}$

932.91

1056.99

1157.92

1293.46

1375.76

1447.51

1491.20

159235

1614.90

1718.00

1673.05
570.34

657.83

701.03

820.20

894.61

961.28

959.46

1023.20

1189.78

1297.60

1271.84 
Table 3.- Comparison of Health care expenditure in Spain compared to other OECD countries (unweighted)

\begin{tabular}{|c|c|c|c|c|c|}
\hline \multicolumn{6}{|c|}{ Spain } \\
\hline Year & GDP $^{1}$ & ExpGDP $^{2}$ & ExpPC $^{3}$ & PubGDP $^{4}$ & PubPC $^{5}$ \\
\hline 2001 & 22577.936 & 7.20 & 1635.00 & 5.13 & 1164.10 \\
\hline 2002 & 24068.216 & 7.30 & 1745.00 & 5.20 & 1244.10 \\
\hline 2003 & 24754.840 & 8.20 & 2025.60 & 5.77 & 1425.70 \\
\hline 2004 & 25956.475 & 8.20 & 2135.10 & 5.79 & 1506.70 \\
\hline 2005 & 27392.007 & 8.30 & 2274.10 & 5.89 & 1613.90 \\
\hline 2006 & 30405.925 & 8.40 & 2552.50 & 6.02 & 1828.60 \\
\hline 2007 & 32233.471 & 8.50 & 2738.60 & 6.11 & 1968.90 \\
\hline 2008 & 33129.605 & 8.90 & 2965.50 & 6.51 & 2169.40 \\
\hline 2009 & 32149.771 & 9.60 & 3096.70 & 7.06 & 2314.10 \\
\hline 2010 & 31903.798 & 9.60 & 3055.70 & 6.99 & 2266.80 \\
\hline
\end{tabular}

\begin{tabular}{lccccc}
\multicolumn{5}{c}{ Only Beveridge countries } \\
\hline Country and year & GDP $^{1}$ & ExpGDP $^{2}$ & ExpPC $^{3}$ & PubGDP $^{4}$ & PubPC $^{5}$ \\
\hline United Kingdom & 24252.645 & 6.90 & 1676.90 & 5.56 & 1352.00 \\
1999 & & & & & \\
Italy 1999 & 24344.720 & 7.70 & 1884.70 & 5.45 & 1333.40 \\
\hline Finland 2000 & 25674.229 & 7.20 & 1853.50 & 5.13 & 1320.80 \\
Italy 2000 & 25757.549 & 8.00 & 2064.40 & 5.80 & 1496.90 \\
\hline Sweden 1999 & 25976.341 & 8.20 & 2129.50 & 7.03 & 1825.50 \\
United Kingdom & 26072.442 & 7.00 & 1834.40 & 5.52 & 1445.90 \\
2000 & & & & & \\
\hline Italy 2004 & 27528.238 & 8.60 & 2371.70 & 6.53 & 1801.50 \\
Finland 2002 & 27531.343 & 7.80 & 2149.60 & 5.65 & 1557.50 \\
United Kingdom & 27567.772 & 7.30 & 2001.60 & 5.81 & 1591.90 \\
2001 & & & & & \\
\hline & & & & & \\
Italy 2006 & 30399.033 & 9.00 & 2727.00 & 6.89 & 2088.40 \\
Sweden 2003 & 30420.160 & 9.30 & 2832.10 & 7.63 & 2322.50 \\
Denmark 2003 & 30429.631 & 9.50 & 2893.40 & 8.03 & 2446.30 \\
& & & & & \\
\hline Italy 2009 & 32250.027 & 9.30 & 3004.70 & 7.40 & 2391.70 \\
Denmark 2004 & 32289.640 & 9.70 & 3123.10 & 8.17 & 2631.80 \\
\hline Finland 2006 & 33140.167 & 8.30 & 2765.50 & 6.21 & 2069.80 \\
Denmark 2005 & 33195.883 & 9.80 & 3243.00 & 8.28 & 2739.50 \\
Ireland 2002 & 33273.542 & 7.00 & 2335.60 & 5.34 & 1781.60 \\
& & & & & \\
\hline Italy 2009 & 32250.027 & 9.30 & 3004.70 & 7.40 & 2391.70 \\
Denmark 2004 & 32289.640 & 9.70 & 3123.10 & 8.17 & 2631.80 \\
\hline & & & & & \\
Italy 2007 & 32056.400 & 8.60 & 2769.00 & 6.58 & 2119.70 \\
\hline
\end{tabular}

1 GDP per capita US dollars, PPPs; 2 Total health expenditure, \% GDP; 3 Total health expenditure per capita US\$ PPP; 4 Public health expenditure, \% GDP; 5 Public health expenditure, per capita US\$ PPP 
Figure 1a.- Spain. Difference with respect to that expected (positive, above; negative below standard) Total expenditure, percentage of GDP, as results from equation (1). Beveridge-Douglas sample. Weighted by GDP.

Figure 1b.- All countries in relation to the Beveridge-Douglas standard. Difference with respect to that expected. Total expenditure in percentage of GDP as results from equation (1), weighted by GDP.

Figure 1c.- Spain. Difference with respect to that expected. (Positive, above; negative below standard) Total expenditure minus out-of pocket expenditure, percentage of GDP, as results from equation (1). BeveridgeDouglas sample. Weighted by GDP.

Figure 1d- All countries in relation to the Beveridge-Douglas standard. Difference with respect to that expected. Total expenditure minus out-ofpocket expenditure in percentage of GDP as results from equation (1), weighted by GDP.

Figure 2a.- Spain. Difference with respect to that expected. Total expenditure per capita US\$ PPP as results from equation (2). BeveridgeDouglas sample, weighted by population.

Figure 2b.- Spain in relation to the rest of Beveridge. Difference with respect to that expected. Total expenditure per capita US\$ PPP as results from equation (2), weighted by population.

Figure 2c.- Spain. Difference with respect to that expected. Total expenditure per capita US\$ PPP minus out-of-pocket expenditure as results from equation (2). Beveridge-Douglas sample. Weighted by population.

Figure 2d.- Spain in relation to the rest of Beveridge countries. Difference with respect to that expected. Total expenditure per capita US\$ PPP minus out-of-pocket expenditure as results from equation (2), weighted by population.

Figure 3a.- Spain. Difference with respect to that expected. Public expenditure, percentage of GDP as results from equation (1). BeveridgeDouglas sample. Weighted by GDP.

Figure 3b.- Spain in relation to the rest of Beveridge-Douglas countries. Difference with respect to that expected. Public expenditure as percentage of GDP as results from equation (1), weighted by GDP.

Figure 3c.- Spain. Difference with respect to that expected. Public expenditure minus out-of-pocket expenditure, percentage of GDP as results from equation (1). Beveridge-Douglas sample. Weighted by GDP. 
Figure 3d.- Spain in relation to the rest of Beveridge-Douglas countries. Difference with respect to that expected Public expenditure minus out-ofpocket expenditure as percentage of GDP as results from equation (1), weighted by GDP.

Figure 4a.- Spain. Difference with respect to that expected. Public expenditure per capita US\$ PPP as results from equation (2). BeveridgeDouglas sample. Weighted by population.

Figure 4b.- Spain in relation to the rest of Beveridge-Douglas countries. Difference with respect to that expected. Public expenditure per capita US\$ PPP as results from equation (2), weighted by population.

Figure 4c.- Spain. Difference with respect to that expected. Public expenditure per capita US\$ PPP minus out-of-pocket expenditure as results from equation (2). Beveridge-Douglas sample. Weighted by population.

Figure 4d.- Spain in relation to the rest of Beveridge-Douglas countries. Difference with respect to that expected. Public expenditure per capita US\$ PPP minus out-of-pocket expenditure as results from equation (2), weighted by population. 
Click here to download high resolution image

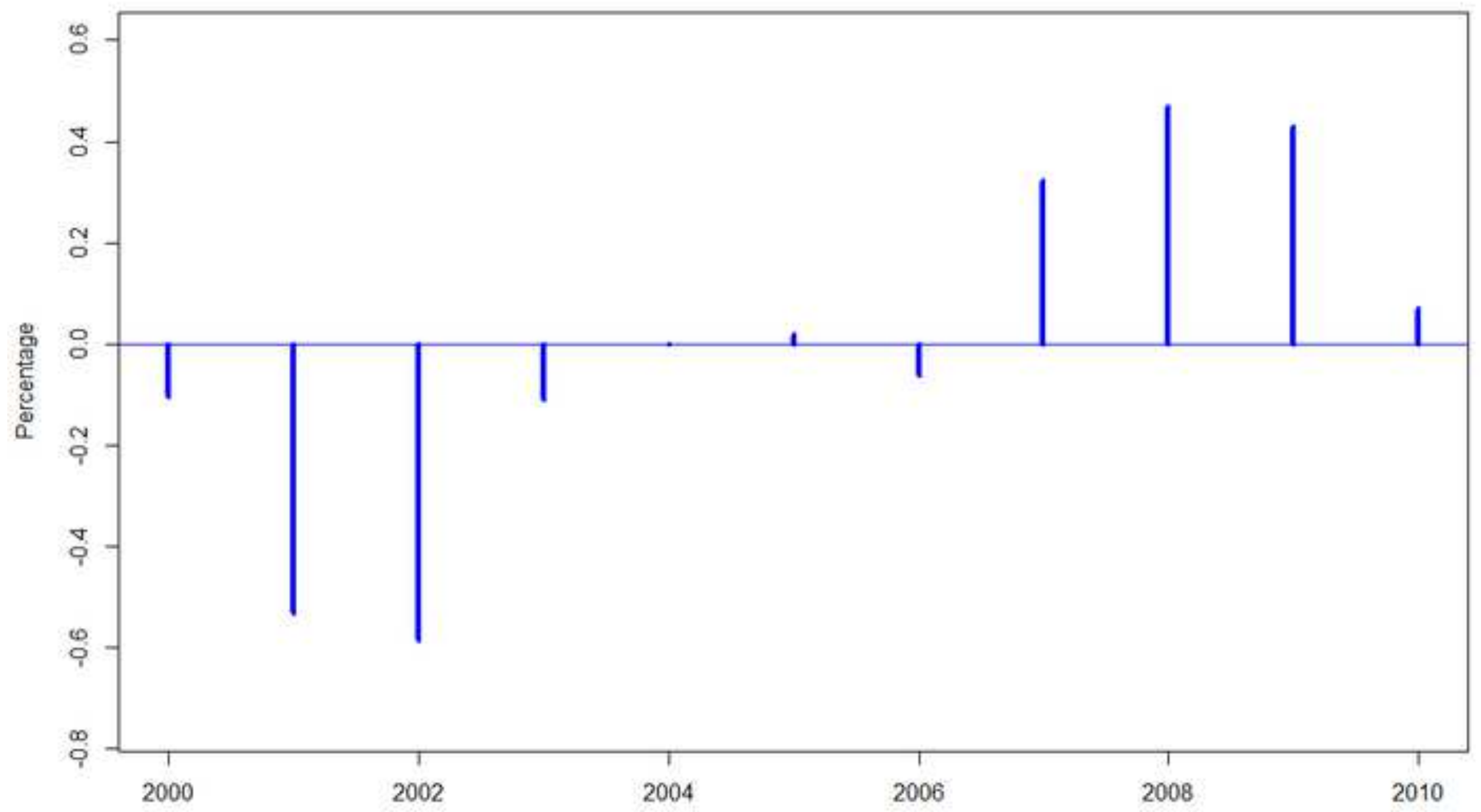



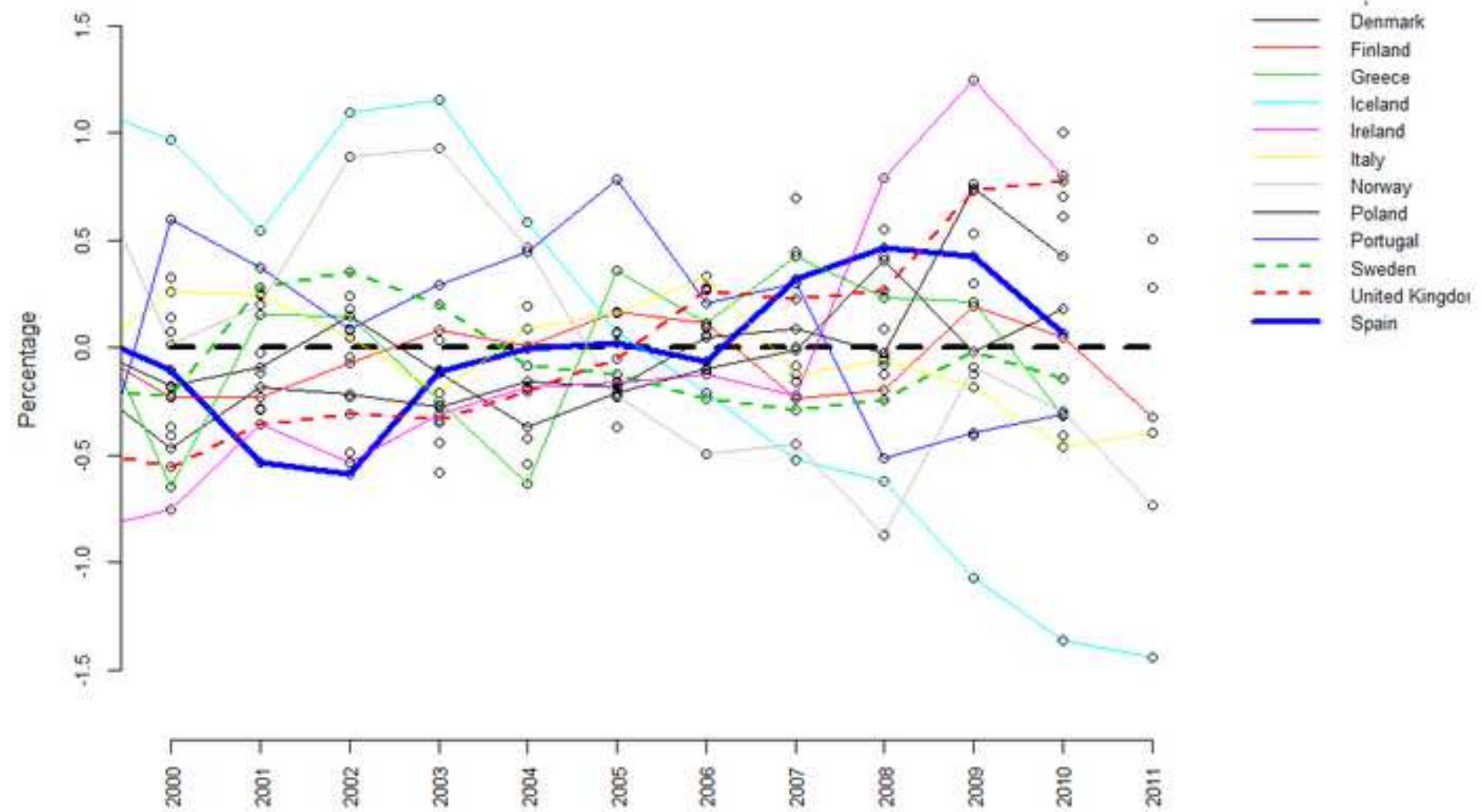
Figure 1c
Click her

Click here to download high resolution image
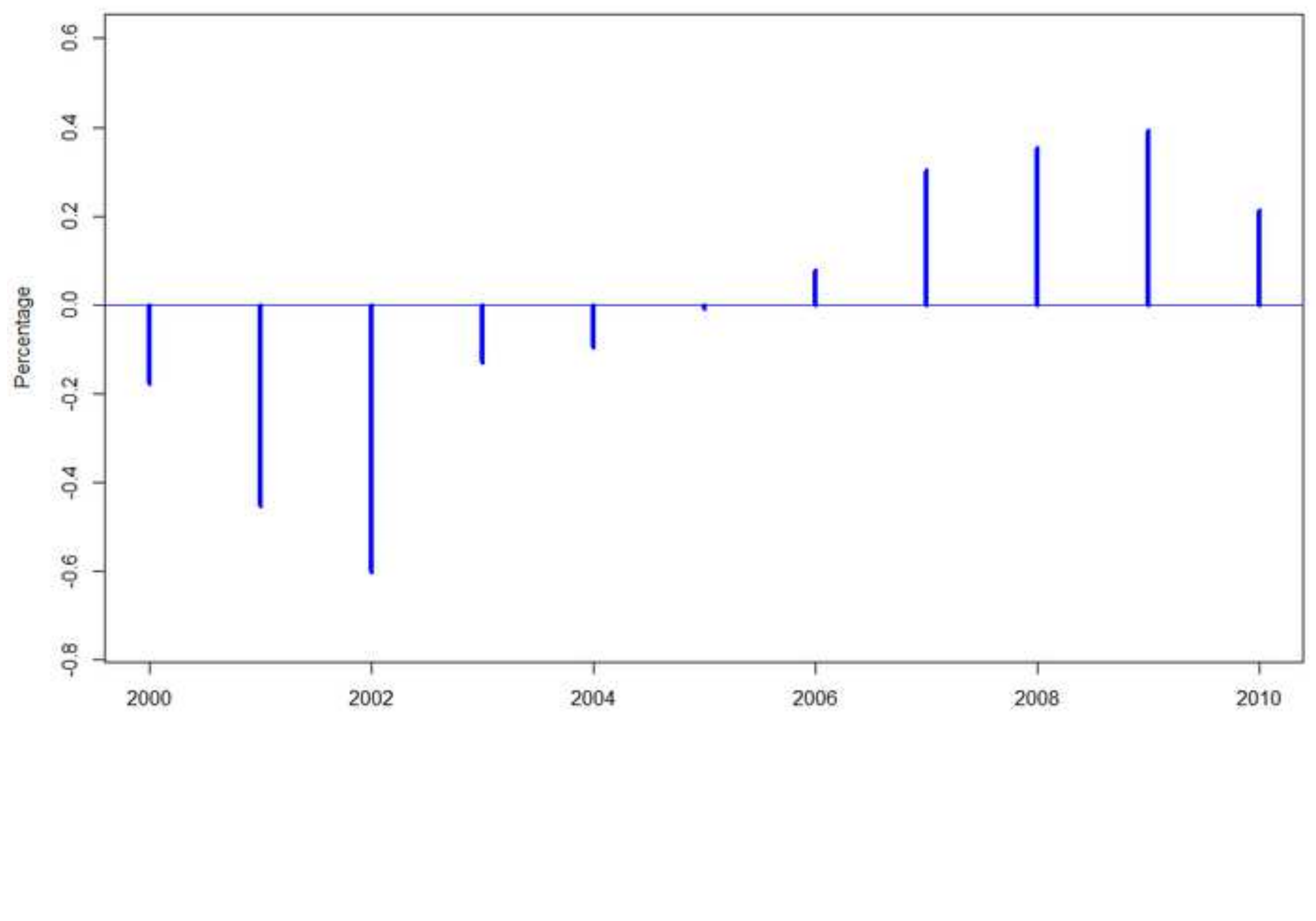

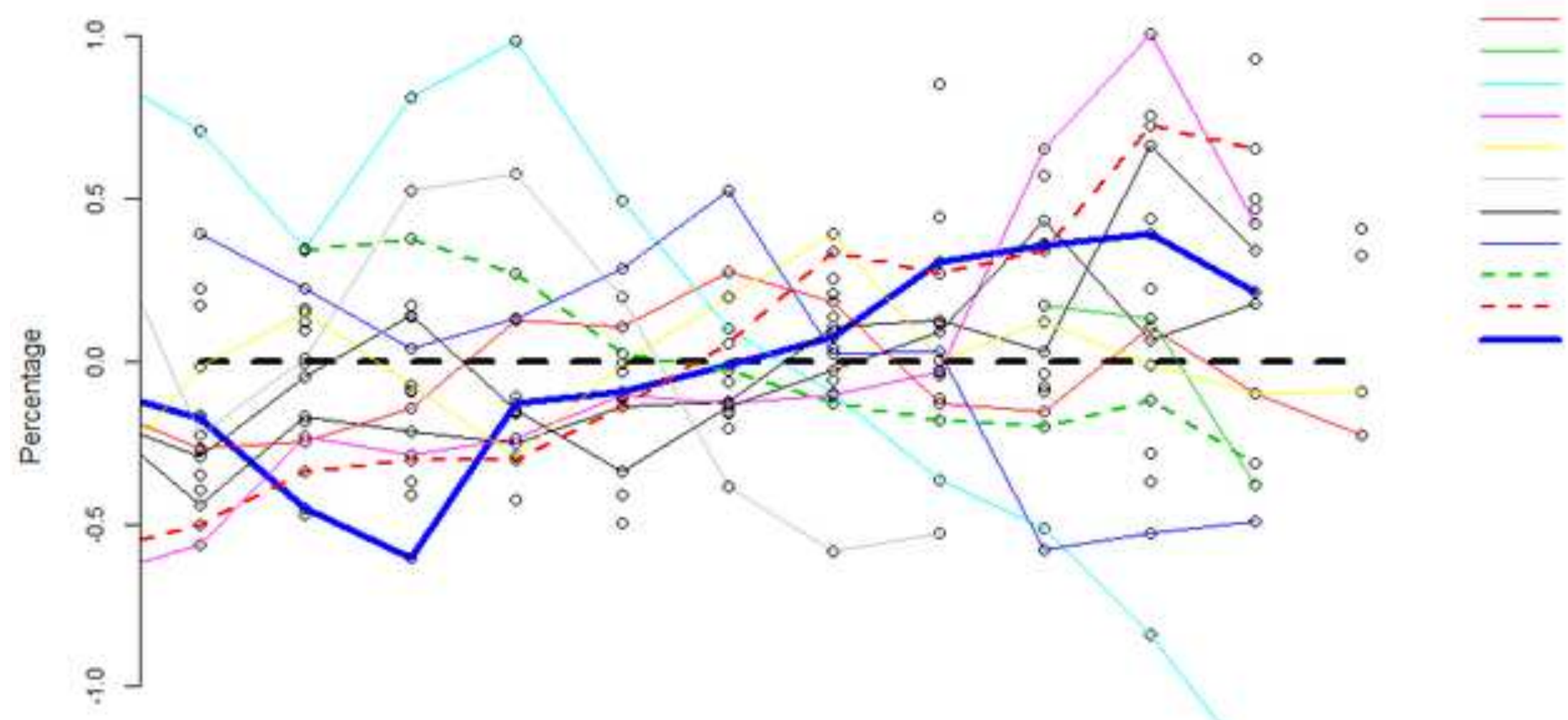

Denmark

Finland

Greece

Iceland

Ireland.

traly

Norway

Poland

Portugal

- - Sweden

-. United Kingdor

Spain.

\begin{tabular}{|c|c|c|c|c|c|c|c|c|c|c|}
\hline$\Gamma$ & 1 & 1 & 1 & $T$ & 1 & 1 & 1 & $T$ & 1 & $T$ \\
\hline & $\overline{8}$ & 용 & ళ্्্ & ह్ర & '용 & 8 & 용 & 总 & ஜ্ৰ & 융 \\
\hline
\end{tabular}


Click here to download high resolution image

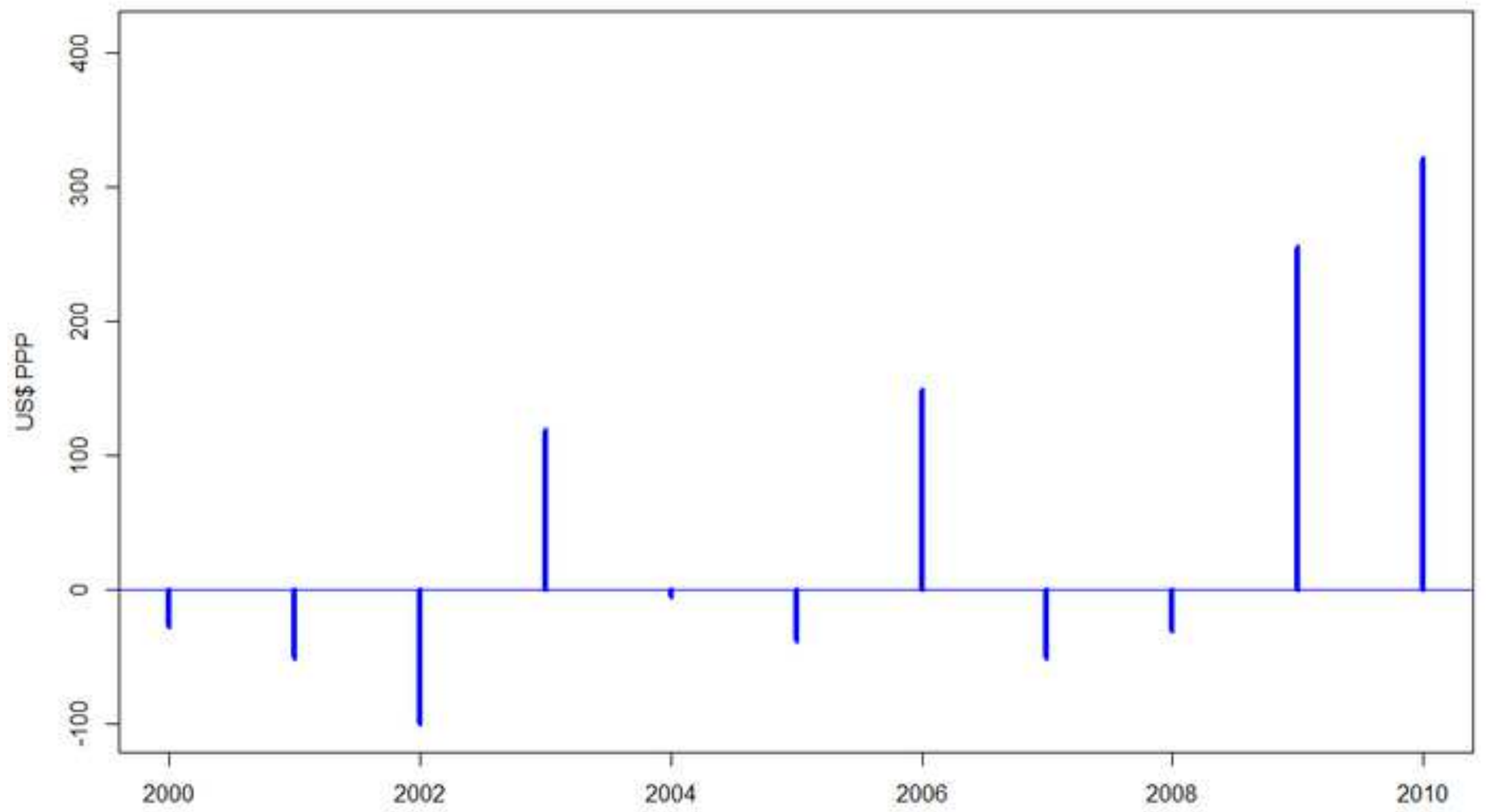




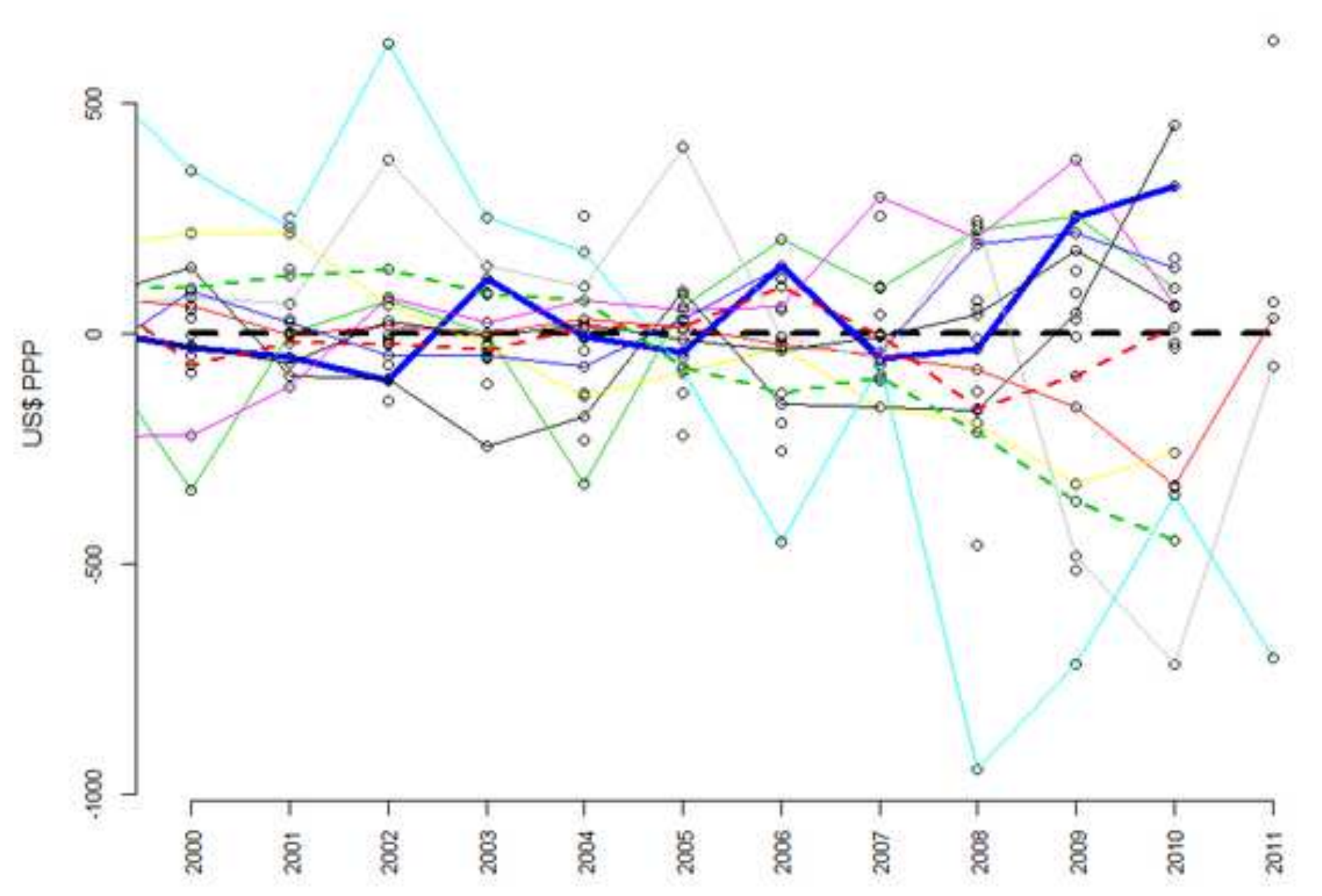

- Poland

$\ldots$ Portugal

-.. United Kingdor

Spain 
Click here to download high resolution image

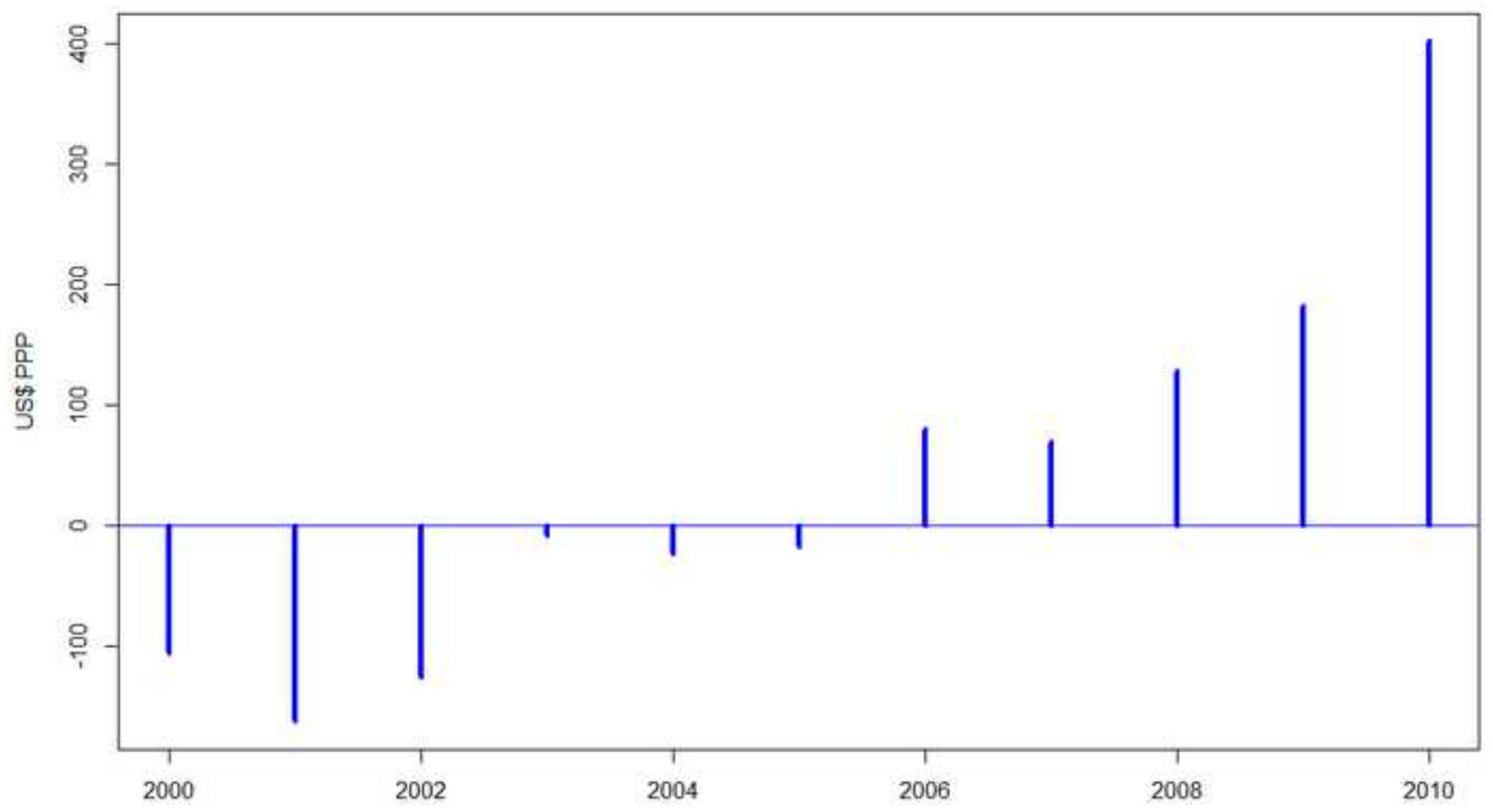



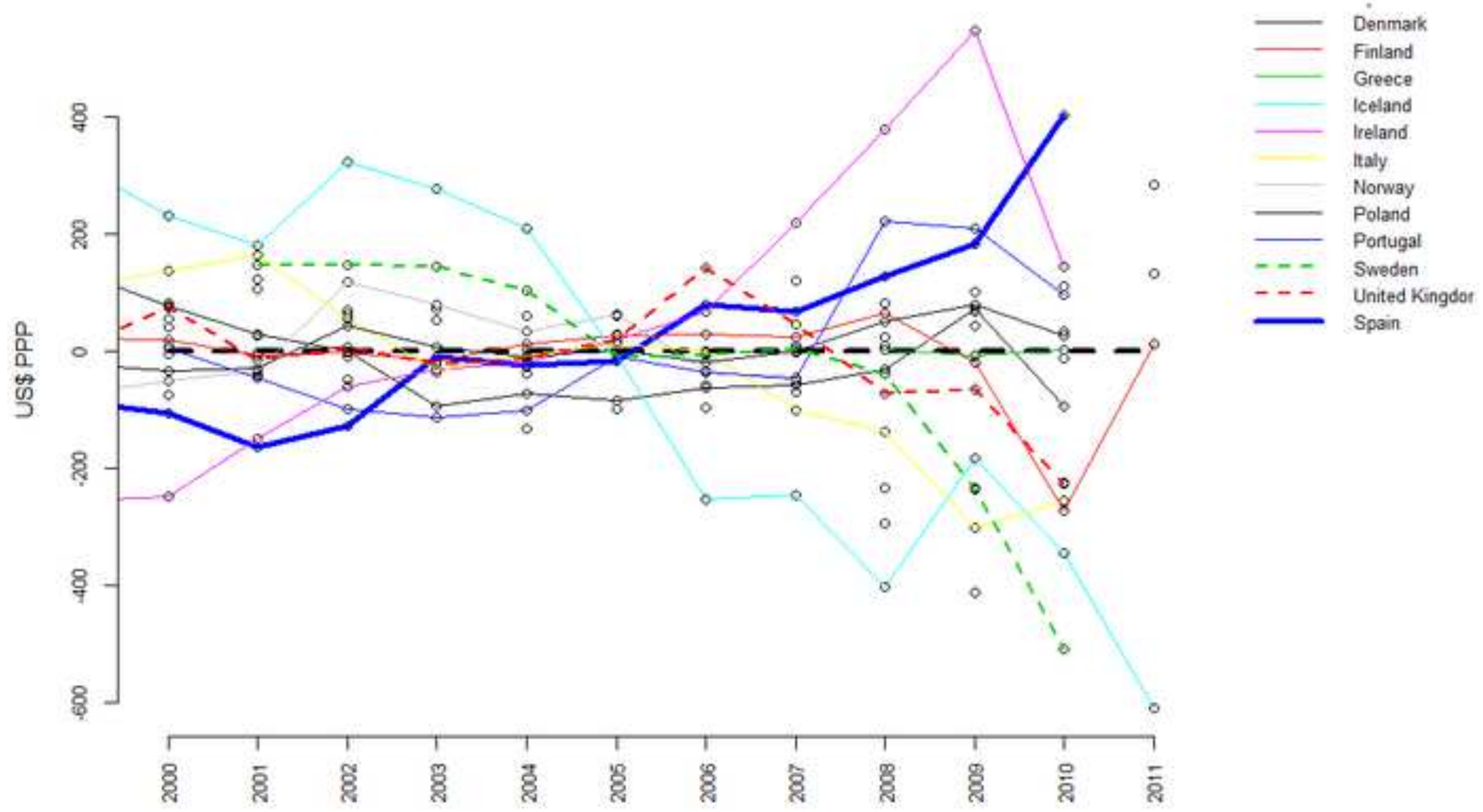

Figure $2 \mathrm{~d}$
Click here to download high resolution image

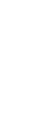

(n)

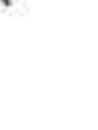

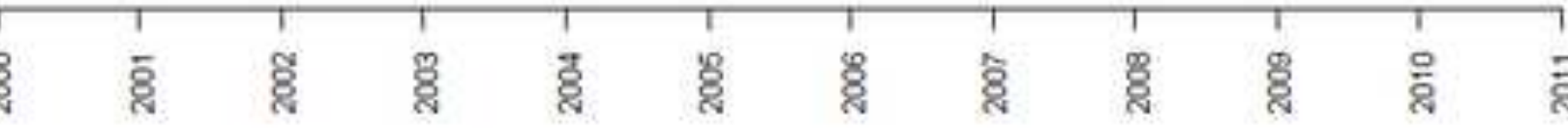

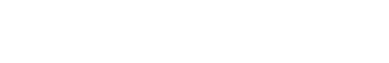


Click here to download high resolution image

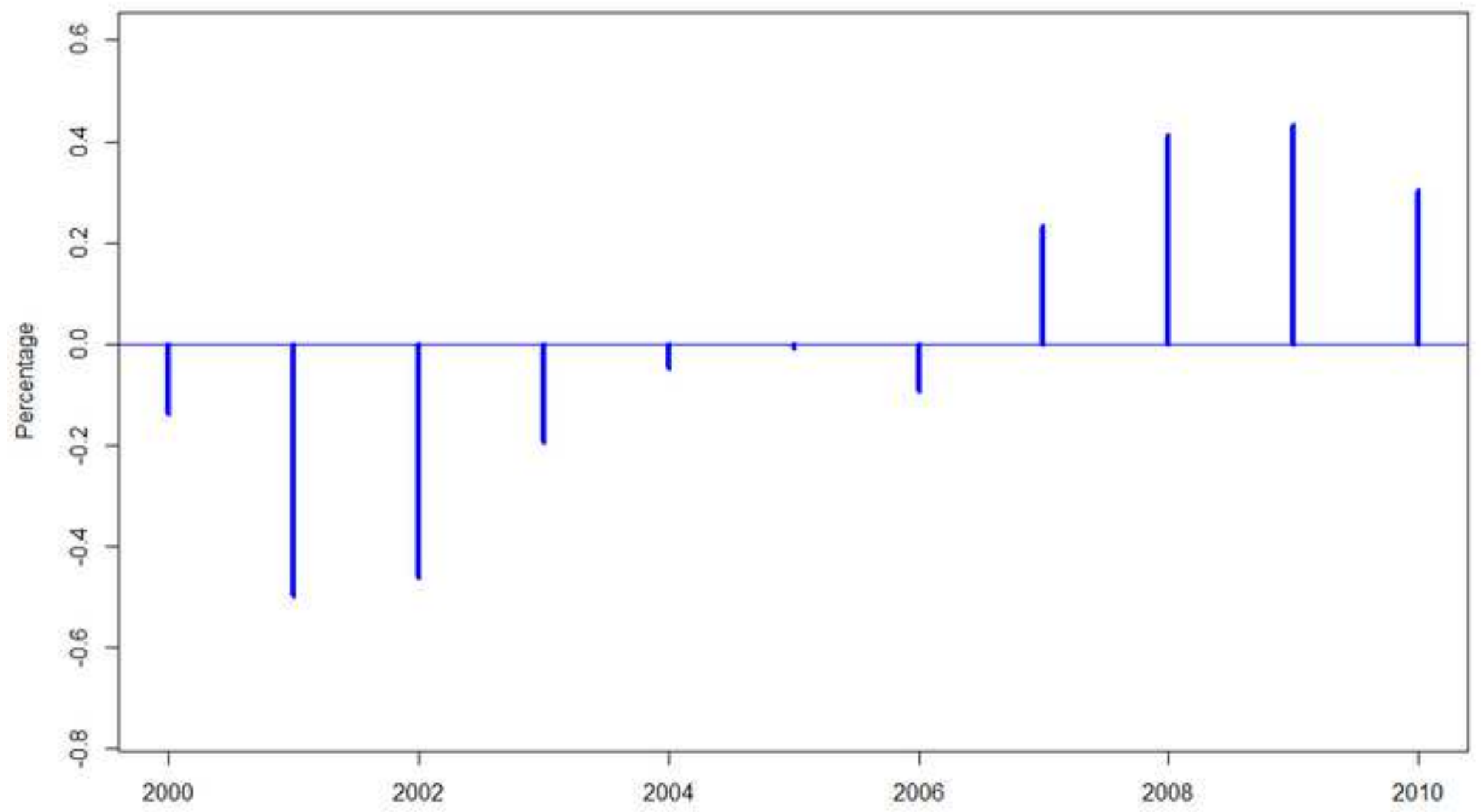




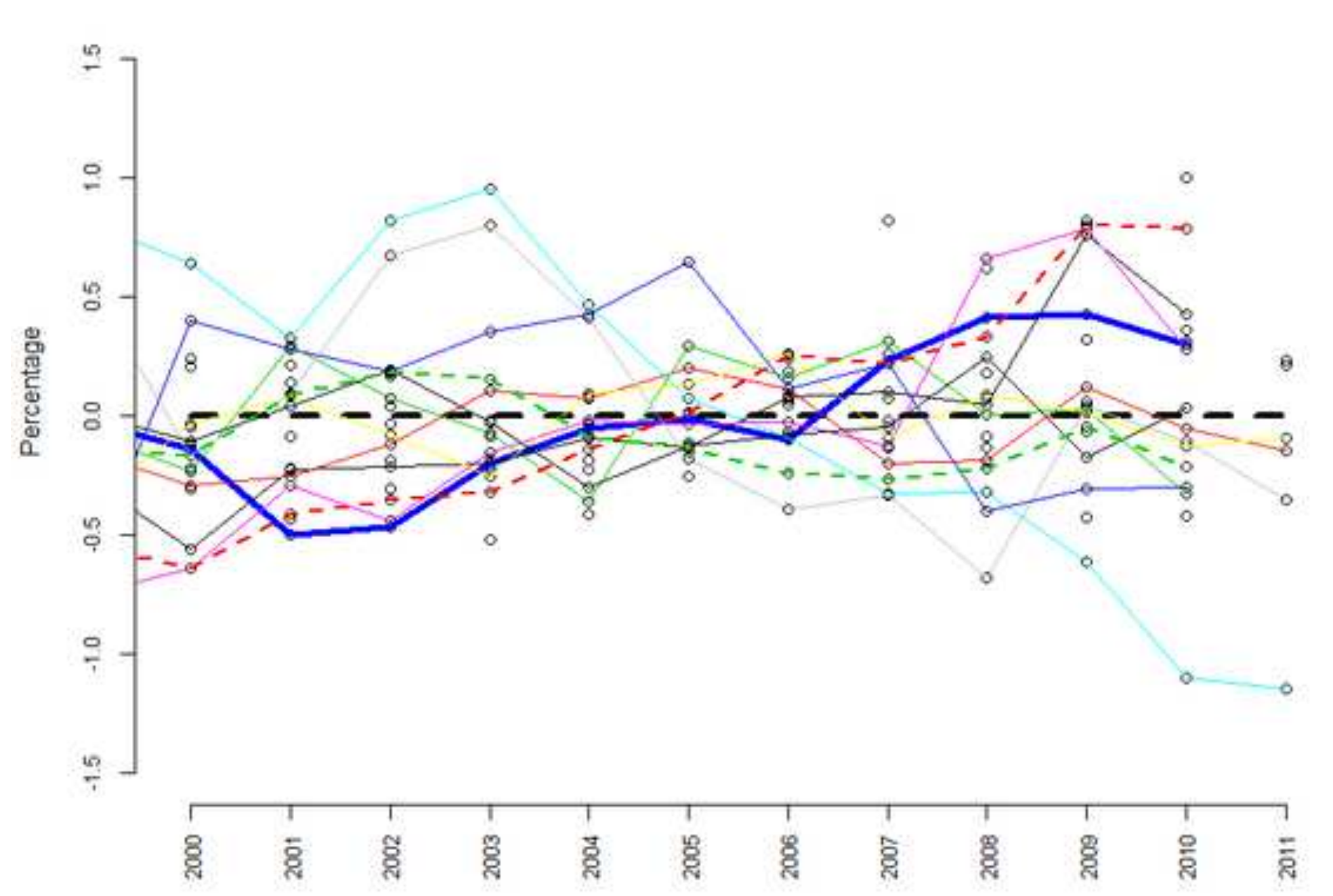

- Poland

- Portugal

... United Kingdor

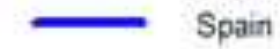


Click here to download high resolution image

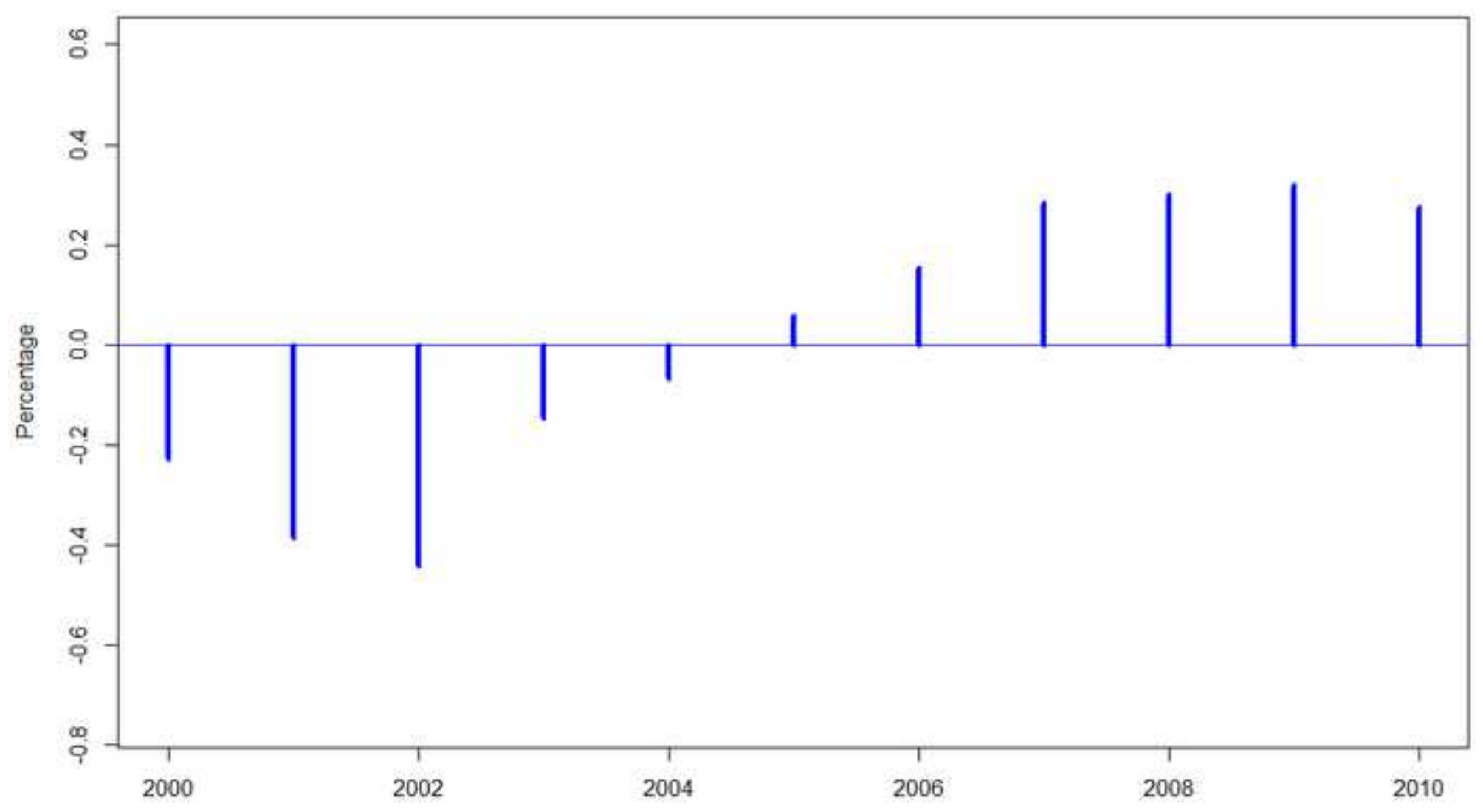




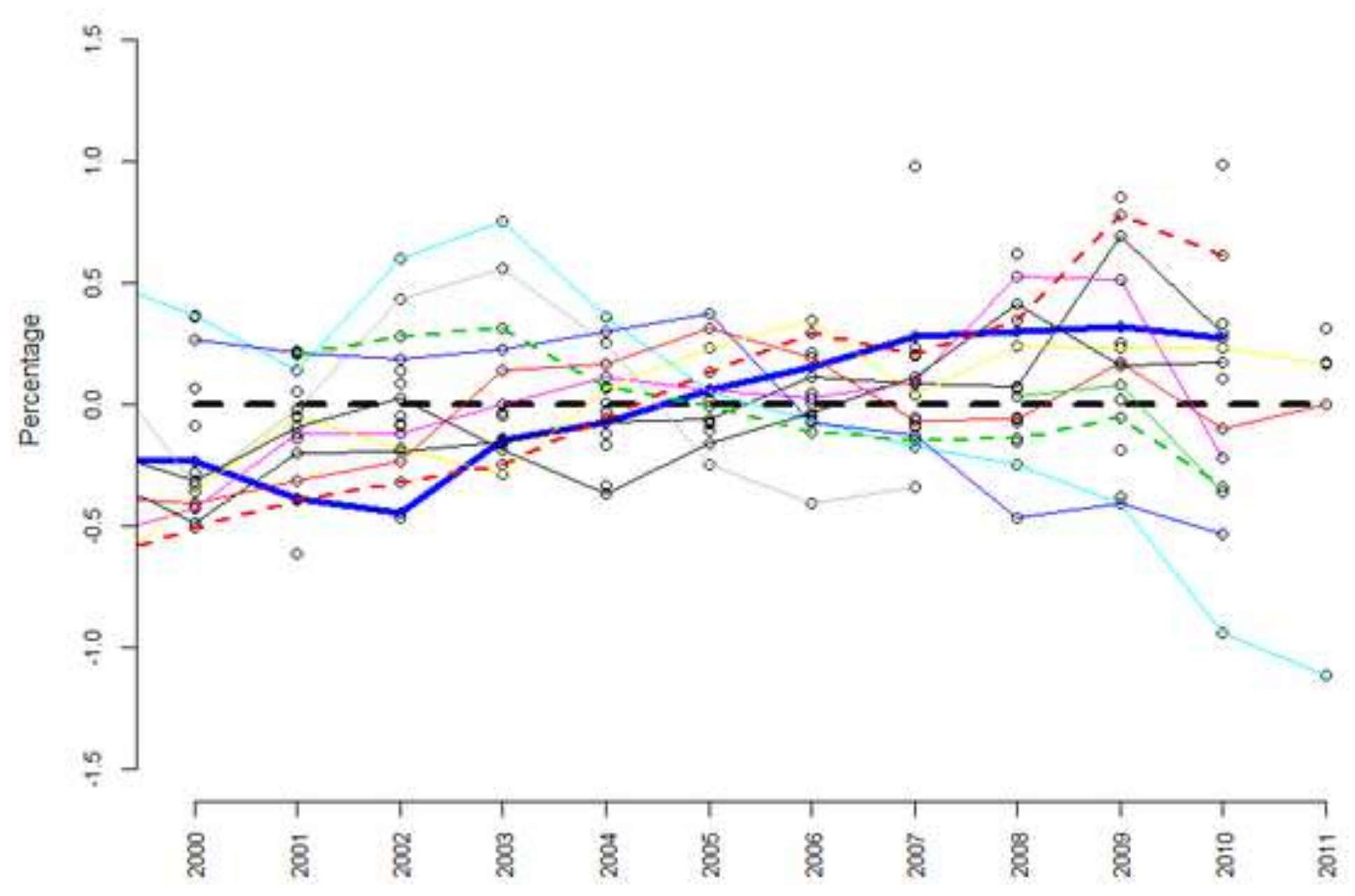


Click here to download high resolution image

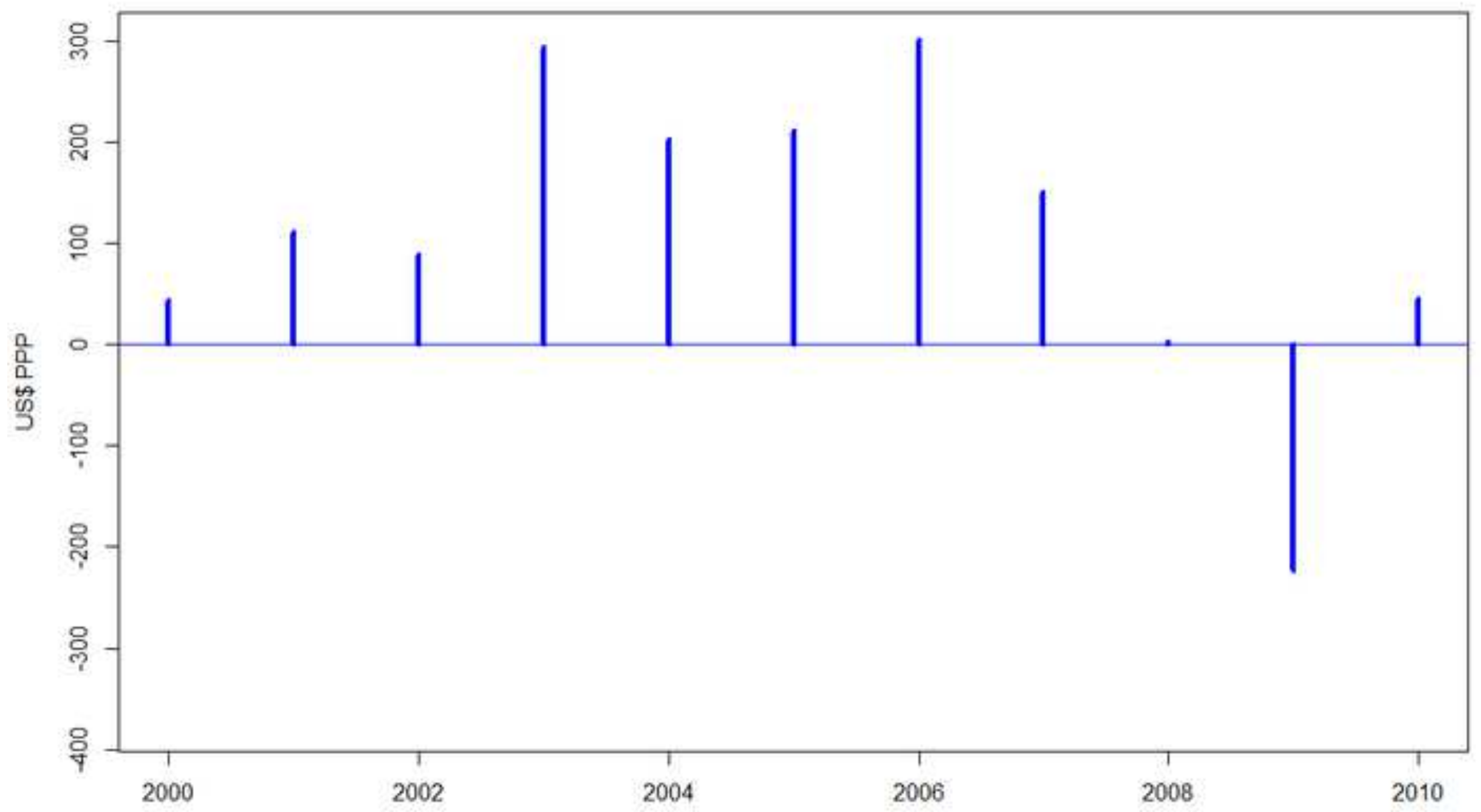


Click here to download high resolution image

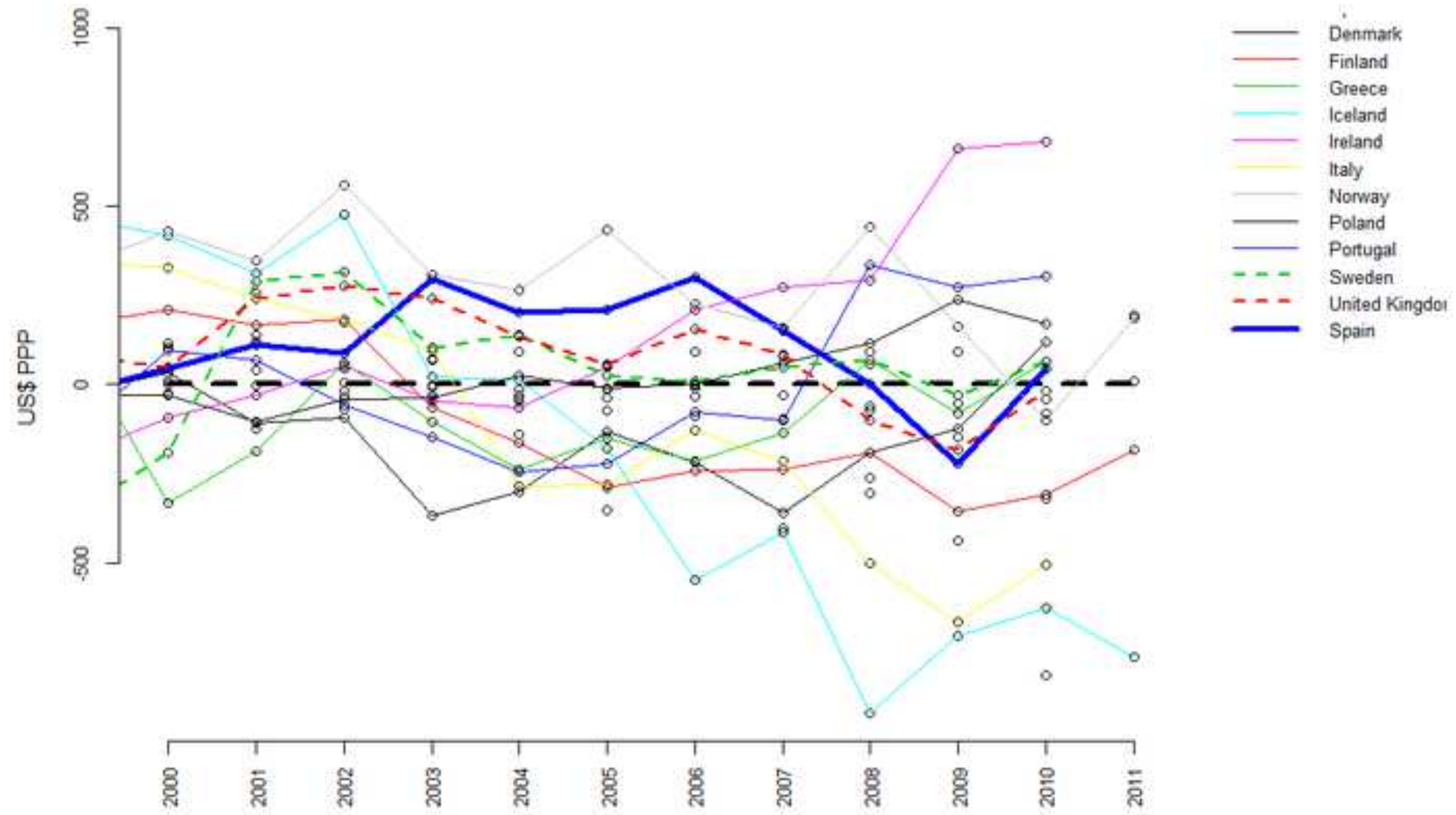


Click here to download high resolution image

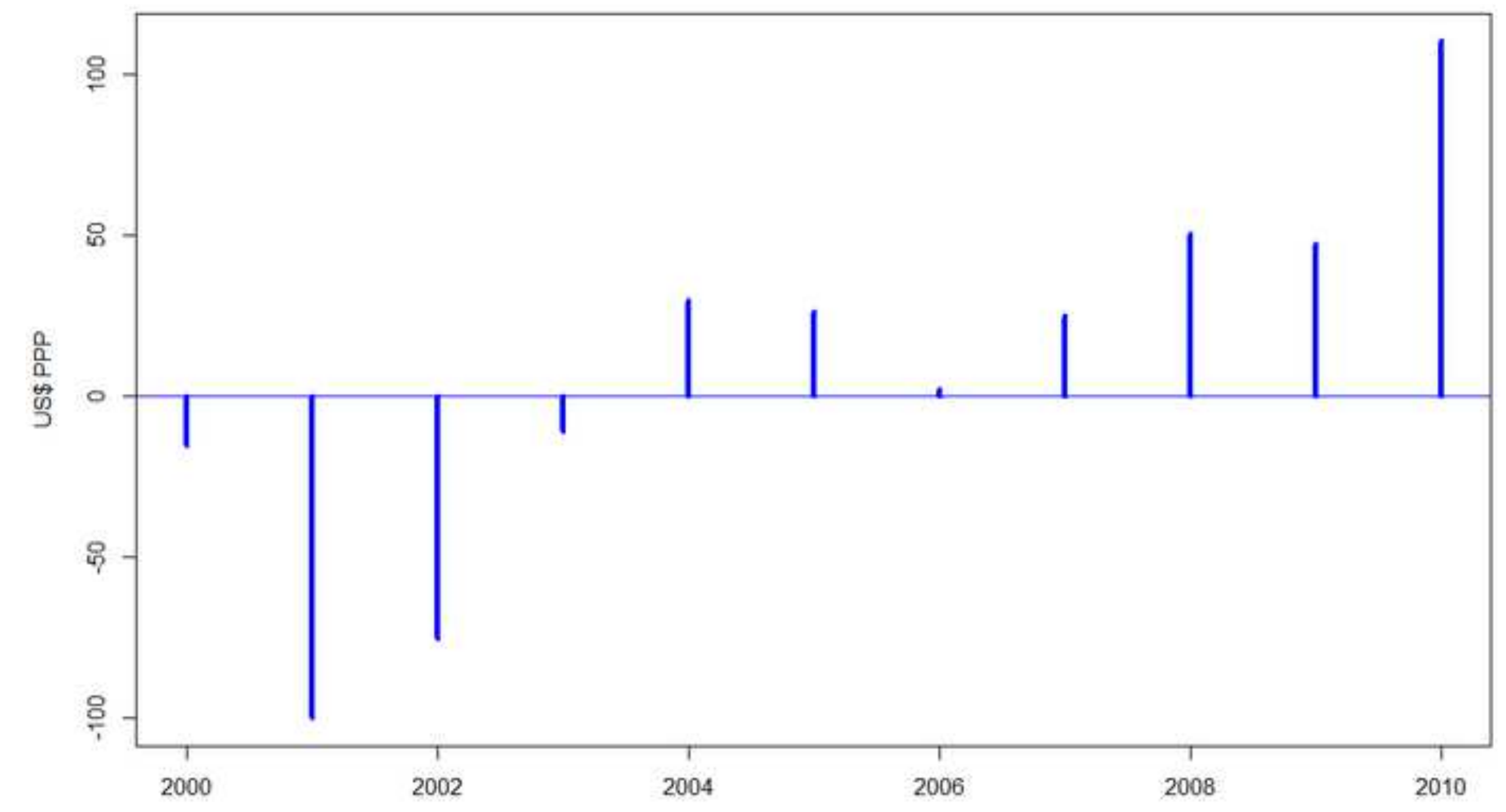


Click here to download high resolution image

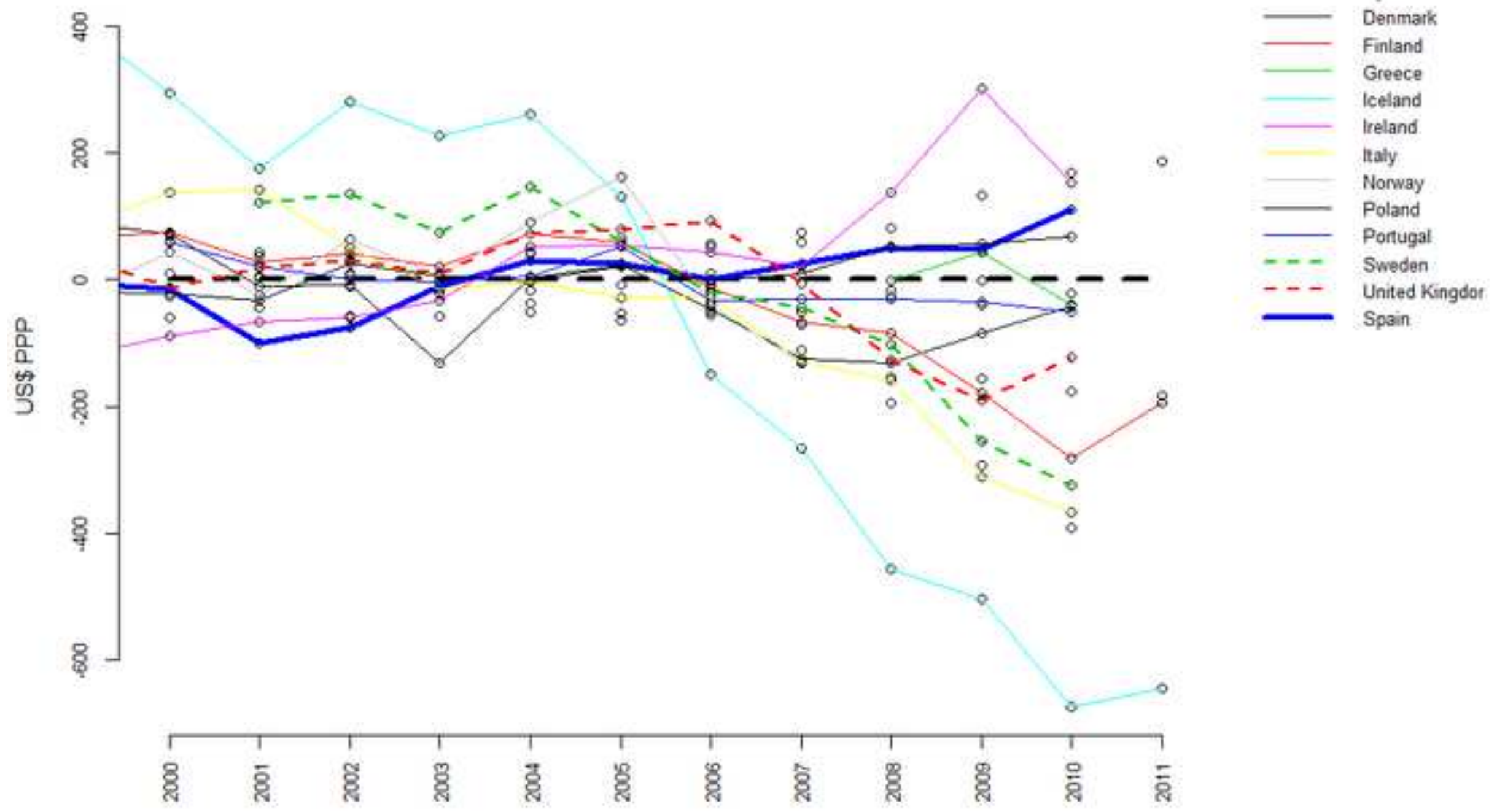

